\title{
¿Evaluation of a Physics-Based Tropical Cyclone Rainfall Model for Risk Assessment
}

\author{
DAZHI XI, NiNG LIN, AND JAMES SMITH \\ Department of Civil and Environmental Engineering, Princeton University, Princeton, New Jersey
}

(Manuscript received 5 February 2020, in final form 15 June 2020)

\begin{abstract}
Heavy rainfall generated by landfalling tropical cyclones (TCs) can cause extreme flooding. A physicsbased TC rainfall model (TCRM) has been developed and coupled with a TC climatology model to study TC rainfall climatology. In this study, we evaluate TCRM with rainfall observations made by satellite (of North Atlantic TCs from 1999 to 2018) and radar (of 36 U.S. landfalling TCs); we also examine the influence on the rainfall estimation of the key input to TCRM - the wind profile. We found that TCRM can simulate relatively well the rainfall from TCs that have a coherent and compact structure and limited interaction with other meteorological systems. The model can simulate the total rainfall from TCs well, although it often overestimates rainfall in the inner core of TCs, slightly underestimates rainfall in the outer regions, and renders a less asymmetric rainfall structure than the observations. It can capture rainfall distribution in coastal areas relatively well but may underestimate rainfall maximums in mountainous regions and has less capability to accurately simulate TC rainfall in higher latitudes. Also, it can capture the interannual variability of TC rainfall and averaged features of the time series of TC rainfall but cannot accurately reproduce the probability distribution of short-term $(1 \mathrm{~h})$ rainfall. Among the tested theoretical wind profile inputs to TCRM, a complete wind profile that accurately describes the wind structure in both the inner ascending and outer descending regions of the storm is found to perform the best in accurately generating various rainfall metrics.
\end{abstract}

KEYWORDS: Tropical cyclones; Rainfall; Model evaluation/performance

\section{Introduction}

Tropical cyclones (TCs) are major natural disasters that affect many countries around the world. Over the past two centuries, 1.9 million deaths have been attributed to hazards related to TCs, including strong wind, intense rainfall, and storm surge. In China, during 19832006, seven tropical cyclones made landfall in mainland China and Hainan Province, causing economic losses of 28.7 billion yuan and killing 472 people on average each year (Zhang et al. 2009). In the United States, Hurricane Harvey (2017) alone caused 106 deaths and an economic loss of $\$ 125$ billion dollars, making it among the costliest natural disasters in U.S. history. Heavy rainfall is one of the major hazards associated with TCs. Recent severe TC rainfall cases include Hurricane Harvey in 2017, which set the record for extreme rainfall, with precipitation exceeding $1000 \mathrm{~mm}$ near Houston, and Hurricane

๑ Denotes content that is immediately available upon publication as open access.

Corresponding author: Dazhi Xi, dxi@princeton.edu
Florence (2018), which was record-breaking for the Carolinas, with extreme precipitation exceeding $700 \mathrm{~mm}$. Studies on historical events (Risser and Wehner 2017; Touma et al. 2019) and climate projections (Emanuel 2017) both show an increasing trend in extreme TC precipitation, suggesting a higher probability of events like Hurricane Harvey in the future climate.

Rainfall in TCs can be categorized into two forms, convective and stratiform rainfall (Houze 2010). Convective rainfall dominates rainfall in the eyewall and primary rainbands and occurs also in isolated rainbands. Stratiform rainfall is weaker but covers larger areas. TC rainfall is related to TC intensity, and the rain rate is varying with radius, with on average highest rain rates occurring in the eyewall region and lower rain rates in outer radii (Lonfat et al. 2004). Recent studies also found that the highest precipitation from landfalling TCs are often caused by tropical storms weakened from major hurricanes (Touma et al. 2019). Several mechanisms have been found to be important for TC rainfall. Frictional effects are of major importance for producing heavy rainfall and were found to have a strong impact on the location of convection and storm rainfall asymmetry (Shapiro 1983). Topographic 
forcing can significantly influence TC rainfall, especially in mountainous regions (Cheung et al. 2008; Yang et al. 2011). Vertical wind shear was found to influence the favorable location of eyewall convection (Braun and $\mathrm{Wu} 2007$ ) and to modulate the location of rainbands (Willoughby et al. 1984). The favorable location for TC rainfall in Northern (Southern) Hemisphere is down shear left (right) (Rogers et al. 2003; Chen et al. 2006). Previous research found that vortex stretching (the effect of storm intensification and weakening associated with vortex spinup and spindown) can also affect TC rainfall (Lu et al. 2018). Furthermore, extratropical transitioning storms have been found being able to produce heavy rainfall, especially in higher-latitude regions (Harr and Elsberry 2000; Atallah and Bosart 2003; Liu et al. 2017, 2020).

Several approaches have been employed to simulate TC rainfall. High-resolution climate models enable the explicit simulation of TCs and have been used to study the future changes of TC rainfall climatology (Liu et al. 2018; Bacmeister et al. 2018; Vecchi et al. 2019). However, it is computationally expensive to generate a large number of possible TC scenarios for risk assessment by running highresolution climate models. To overcome this challenge, TC climatology models have been developed to efficiently generate synthetic storms under large-scale climate projections (Emanuel 2006; Lee et al. 2018; Jing and Lin 2020). Various proposed TC rainfall models (Tuleya et al. 2007; Lonfat et al. 2007; Langousis and Veneziano 2009a; Zhu et al. 2013) can be used to evaluate TC rainfall climatology based on the generated synthetic storms.

Based on satellite observations, Tuleya et al. (2007) developed a statistical model to simulate TC rainfall profiles (RCLIPER) as a function of TC intensity. The model was further improved by Lonfat et al. (2007) to account for rainfall asymmetry caused by topographic and shear effects. In addition to the statistical approach, Langousis and Veneziano (2009a) developed a TC rainfall model based on basic thermodynamics and TC boundary layer theory. The model accounts for the azimuthal asymmetries in surface friction related to storm motion, but it does not account for the interaction of the storm with its environment (e.g., wind shear, topography). First introduced by Zhu et al. (2013), a physics-based tropical cyclone rainfall model (TCRM) has been developed to account for major rainfall generation mechanisms including frictional, topographic, baroclinic (shear), and vortex stretching effects. Not only accounting for more rainfall mechanisms, TCRM is also computationally more efficient than the physicsbased model of Langousis and Veneziano (2009a); TCRM has been applied for TC rainfall climatology and risk assessment (Emanuel 2017). Nevertheless, like all other TC rainfall models, TCRM does not account for storm rainbands or interaction with other meteorological systems.
Since being proposed, TCRM has been evaluated in various ways. Zhu et al. (2013) applied the model with synthetic TCs generated according to Emanuel et al. (2008) for Texas and compared the simulated TC rainfall climatology with the estimated climatology based on $60-y r$ rain gauge observations. They found that the rainfall climatology estimated from the coupled simulation compares well with that from observations. Feldmann et al. (2019) used the same coupling method as Zhu et al. (2013) and TCRM with an updated drag coefficient specification to evaluate the estimated TC rainfall climatology in the coastal United States. They found that, in general, the coupled simulation can generate TC rainfall climatology comparable to that estimated from gauge and radar observations; however, the performance of the model is less satisfactory for regions with a large surface roughness gradient. Lu et al. (2018) studied TCRM with a different approach. Rather than investigating the estimated climatology, they compared rainfall generated from TCRM with that from the Weather Research and Forecast (WRF) Model for two historical TCs. They found that TCRM can generate rainfall features similar to those in the full physics model WRF, and when coupled with a hydrology model, TCRM can generate rainfall flood peaks as accurately as WRF. Lu et al. (2018) also studied the influence of the key TCRM input-wind profile-on TCRM rainfall estimation. They found that the Holland (1980, hereafter H80) wind profile performs the best among the four wind profile models that were examined.

Although the studies summarized above have evaluated some aspects of TCRM performance, additional investigations are needed to better understand the capability and limitations of the model. Zhu et al. (2013) and Feldmann et al. (2019) evaluated TCRM in tandem with the synthetic storm algorithm (Emanuel et al. 2008), which has its own uncertainties in the estimation of TC frequency, track, intensity, etc. Also, future studies may require coupling TCRM with other observed or synthetically generated storm datasets, so understanding the intrinsic features and uncertainties of the TCRM itself is needed. Lu et al. (2018) evaluated TCRM against WRF simulations for two historical storms. This evaluation provided insights on the TCRM rainfall mechanisms, but it was limited by the two specific cases selected. In this study, we further evaluate the (updated) TCRM with all historical North Atlantic (NA) TCs from 1999 to 2018, using satellite and radar observations. We investigate the performance of TCRM in reproducing rainfall features of individual storms (such as total rainfall and symmetric and asymmetric rainfall structure), spatial rainfall distribution on the continental United States, and temporal rainfall variability at the interannual, event, and hourly time scales. 
Along with evaluating the model, we analyze the influence of wind profile input on the TCRM simulation, based on the large sample of storms.

The primary goal of this research is to better understand TCRM and its potential for hydroclimatological applications. The outline of the paper is as follows: section 2 discusses the models (TCRM, input wind profile models, and the RCLIPER model as a benchmark) and data used in this study. Section 3 analyzes the ability of TCRM to reproduce rainfall statistics of historical TCs. Discussion of the results of this study and comparison with previous studies ( $\mathrm{Lu}$ et al. 2018; Feldmann et al. 2019) appears in section 4. Section 5 summarizes the conclusions of this study.

\section{Model, data, and analysis}

\section{a. Physics-based TCRM model}

The detailed derivation of the physics based TCRM can be found in Lu et al. (2018); here we briefly summarize the model. In TCRM rainfall is generated from five physical mechanisms: topographic forcing, frictional effect, vortex stretching, baroclinic effect, and radiative cooling. Each physical component generates a vertical velocity, and the total vertical velocity is simply calculated as the sum of the vertical velocities estimated from the five components. Vertical vapor flux can then be computed by multiplying the total vertical velocity with the specific humidity. The rain rate is computed by multiplying the vertical vapor flux with the precipitation efficiency, which is set as 0.9 according to Lu et al. (2018). Lu et al. (2018) found that the frictional effect dominates the rainfall generated by the model, and topographic forcing plays an important role in simulating rainfall in mountainous regions. The model takes TC position, TC wind profile, translation speed, lowlevel specific humidity, and wind shear as inputs. Other parameters for TCRM in this study are set the same as in Lu et al. (2018), except that the lower troposphere height is set as $4000 \mathrm{~km}$ rather than $1000 \mathrm{~km}$ to be more consistent with the theory. The drag coefficient is calculated from surface roughness, following Feldmann et al. (2019). We run TCRM with a horizontal resolution of $0.05^{\circ} \times 0.05^{\circ}$ following Lu et al. (2018), with the sensitivity to the model resolution discussed in section 4.

\section{b. TC wind profile models}

As the TC wind profile is a critical but uncertain input for TCRM, we investigate the influence on the TCRM simulation of the choice of the TC wind profile. Four TC wind profile models that were investigated by $\mathrm{Lu}$ et al. (2018) are used in this study: H80, Emanuel (2004, hereafter E04), Emanuel and Rotunno (2011, hereafter ER11), and Chavas et al. (2015, hereafter C15).
The widely used H80 is a semiempirical wind profile model, based on the gradient wind balance assumption and an empirical distribution of the sea surface pressure. E04 is a theoretical profile that depicts the wind over two distinct regions in the storm, with the outer nonconvecting region derived based on the free-tropospheric thermodynamic balance and boundary layer Ekman dynamic balance and the inner convecting region based on boundary layer angular momentum balance and entropy quasiequilibrium. ER11 provides an improved solution for the inner convecting region that arises from stratification of the outflow due to Kelvin-Helmholtz turbulence generated by the storm. $\mathrm{C} 15$, considered a complete radius wind profile, is a combination of the inner region profile of ER11 and the outer region profile of E04 to achieve an overall improved performance.

All four TC wind profile models require inputs of the maximum sustained wind (Vmax) and radius of maximum wind (RMW) and can be run fast to provide input for TCRM. C15 can also be driven by Vmax and the outer size of the storm (Chavas and Lin 2016), which may be favorable in applications when RMW is uncertain or unknown. Lu et al. (2018) compared the four wind profile models in TCRM simulations for two historical cases and found that H80 performed the best. Here we compare them for a large sample of historical events from 1999 to 2018, with in total 393 TCs included in the analysis.

\section{c. Benchmark RCLIPER model}

To provide a benchmark comparison for TCRM, we also simulate the NA TC rainfall from 1999 to 2018 using the RCLIPER model. RCLIPER (Tuleya et al. 2007) was developed based on the satellite observation of TC rainfall from 1998 to 2000. It is a statistical, axisymmetric model that mimics the radius profile of TC rainfall observed by satellite. The input for RCLIPER is the maximum sustained wind, and no environmental or surface information is used. The RCLIPER model has been used in several studies as a benchmark comparison for TC rainfall simulations (Tuleya et al. 2007; Lonfat et al. 2007). In this study, RCLIPER is run on a 1-h time resolution, and the extent of the simulation is within $600 \mathrm{~km}$ from the TC center.

\section{d. Historical TC and environmental data}

To simulate rainfall from historical storms, observed TC and environmental data as well as topographic data are required. NA TC data from 1999 to 2018 are obtained from IBTrACS (Knapp et al. 2010; updated). It provides 6-hourly TC positions, maximum sustained wind speed, and RMW. Among the IBTrACS data we used in this study, $31 \%$ have missing data of RMW; 
we estimated those RMW values using an empirical formula that models RMW as a function of TC intensity and latitude (Knaff and Zehr 2006). The data are then linearly interpolated to 1-h resolution and used as input for TCRM.

Environmental data include wind shear (difference between $200-\mathrm{hPa}$ wind and $850-\mathrm{hPa}$ wind) averaged within $600-800-\mathrm{km}$ annulus of the TC center and the specific humidity at $925 \mathrm{hPa}$ averaged within $200 \mathrm{~km}$ of the TC, which are extracted from NCEP reanalysis fields (Kalnay et al. 1996; updated). The 6-hourly environmental data from NCEP are also interpolated to 1-h resolutions and used as input for TCRM.

Data for topography height and surface roughness, with a resolution of $0.25^{\circ} \times 0.25^{\circ}$, are obtained from the European Centre for Medium-Range Weather Forecasts (ECMWF; Dee et al. 2011). Following Feldmann et al. (2019), the drag coefficient in TCRM is computed based on the surface roughness data, using the method introduced by Esau (2004).

\section{e. Satellite rainfall observations}

The Tropical Rainfall Measuring Mission (TRMM) is used as the primary data source to evaluate TCRM. TRMM started in service in 1988 and was replaced by the Global Precipitation Mission (GPM) after 2015. Both satellite rainfall observations (SRO) provide rainfall data with a $0.25^{\circ} \times 0.25^{\circ}$ horizontal resolution and 3-h temporal resolution, and only data within $600 \mathrm{~km}$ from the TC center are extracted to represent the rainfall related to the TC (1999-2018, 393 TCs). SRO provides observations on both open ocean and land, thus providing climatological information on TC rainfall that is lacking in ground-based observations. Uncertainties in SRO are reported in previous research, and it is concluded that SRO biases toward underestimating heavy rainfall and overestimating light rainfall (Wright et al. 2015; Berg et al. 2006).

In this study, we focus on the rainfall within $600 \mathrm{~km}$ of the TC center. Although some studies have used the radius of outermost isobar (ROCI) to define the precipitation range (Zhu et al. 2013), our choice of a constant range, which helps in analyzing the average rainfall structure, follows several rainfall climatology studies (Wright et al. 2015; Liu et al. 2017).

\section{f. Radar rainfall observation}

SRO can provide rainfall data for a large spatial area, yet it is limited in spatial and temporal resolutions. To evaluate the capability of TCRM to simulate detailed rainfall patterns and short-term extreme rainfall, amounts of precipitation related to 36 U.S. landfalling TCs from 2002 to 2012 that have at least TS intensity when making landfall are derived from the 4-km, 1-h NCEP Stage IV quantitative precipitation estimation (Lin and Mitchell 2005).
TABLE 1. TCs selected for rainfall time series analysis.

\begin{tabular}{cll}
\hline \hline Year of TC & TC name & \multicolumn{1}{c}{ Selected time period } \\
\hline 2002 & Bertha & 1700 UTC 4 Aug-1300 UTC 9 Aug \\
2002 & Hanna & 2300 UTC 11 Sep-1300 UTC 15 Sep \\
2002 & Isidore & 0600 UTC 25 Sep-1800 UTC 27 Sep \\
2002 & Lili & 0500 UTC 2 Oct-1300 UTC 4 Oct \\
2003 & Bill & 1700 UTC 29 Jun-0100 UTC 3 Jul \\
2003 & Claudette & 1100 UTC 12 Jul-1300 UTC 17 Jul \\
2003 & Grace & 1100 UTC 30 Aug-0700 UTC 2 Sep \\
2003 & Isabel & 0600 UTC 18 Sep-1800 UTC 20 Sep \\
2004 & Charley & 1200 UTC 11 Aug-2300 UTC 15 Aug \\
2004 & Frances & 1700 UTC 2 Sep-1300 UTC 10 Sep \\
2004 & Gaston & 1100 UTC 27 Aug-0100 UTC 1 Sep \\
2004 & Ivan & 1700 UTC 14 Sep-0700 UTC 24 Sep \\
2004 & Jeanne & 0600 UTC 25 Sep-1200 UTC 29 Sep \\
2004 & Matthew & 1100 UTC 8 Oct-0700 UTC 11 Oct \\
2005 & Arlene & 1700 UTC 10 Jun-0800 UTC 14 Jun \\
2005 & Cindy & 2300 UTC 4 Jul-1300 UTC 10 Jul \\
2005 & Dennis & 0000 UTC 10 Jul-0000 UTC 18 Jul \\
2005 & Katrina & 0600 UTC 28 Aug-0600 UTC 31 Aug \\
2005 & Rita & 0600 UTC 23 Sep-0100 UTC 7 Oct \\
2005 & Tammy & 0500 UTC 5 Oct-0100 UTC 7 Oct \\
2006 & Alberto & 1100 UTC 11 Jun-0800 UTC 15 Jun \\
2006 & Ernesto & 1700 UTC 29 Aug-0700 UTC 4 Sep \\
2007 & Barry & 1800 UTC 1 Jun-1300 UTC 5 Jun \\
2007 & Erin & 0000 UTC 15 Aug-1900 UTC 19 Aug \\
2007 & Humberto & 0600 UTC 12 Sep-1300 UTC 14 Sep \\
2008 & Dolly & 1200 UTC 22 Jul-0100 UTC 27 Jul \\
2008 & Fay & 0700 UTC 18 Aug-0600 UTC 28 Aug \\
2008 & Gustav & 0600 UTC 31 Aug-1300 UTC 5 Sep \\
2008 & Hanna & 1800 UTC 4 Sep-1800 UTC 7 Sep \\
2008 & Ike & 0700 UTC 12 Sep-0600 UTC 15 Sep \\
2010 & Hermine & 1800 UTC 6 Sep-0100 UTC 10 Sep \\
2011 & Irene & 0000 UTC 21 Aug-0000 UTC 24 Aug \\
2011 & Lee & 2300 UTC 1 Sep-1900 UTC 6 Sep \\
2012 & Beryl & 1100 UTC 25 May-1900 UTC 31 May \\
2012 & Isaac & 0600 UTC 28 Aug-0600 UTC 1 Sep \\
2012 & Sandy & 1200 UTC 29 Oct-1200 UTC 31 Oct \\
\hline & & \\
\hline
\end{tabular}

Table 1 summarizes the 36 TCs selected, with the time period we used to extract Stage IV observation. Although Stage IV provides some observations over the ocean near the coastlines, in this study we use only the data over land to analyze the rainfall.

\section{g. Evaluation analysis}

We first compare rainfall simulated by TCRM for individual storms with SRO. However, as TCRM is a simplified model developed mainly for risk analysis, we focus more on the statistics of TC rainfall modeled by TCRM and evaluate the overall performance of the model for the entire storm sample. We investigate the performance of TCRM in reproducing rainfall features of individual storms as well as the spatial and temporal variation of rainfall integrated or averaged over all storms.

To study rainfall features of individual storms, we compare simulated and observed storm total rainfall 
(STR) and symmetric and asymmetric TC-centered rainfall structure. We define STR as

$$
\operatorname{STR}=\int_{0}^{T} \int_{0}^{600} \int_{0}^{2 \pi} \operatorname{TCR}(t, r, \theta) 2 \pi r d t d r d \theta,
$$

where $\operatorname{TCR}(t, r, \theta)$ represents the TC rainfall at $r \mathrm{~km}$ from the TC center, at directional angle $\theta$ relative to the direction of motion, and at time $t$. It is noted that STR is mathematically similar to the power dissipation (PD) of storms, which is the integration of the product of the cube of wind magnitude, air density, and drag coefficient, describing the total power dissipated over the storm's lifetime (Emanuel 2005). Both the correlation of simulated and observed STR and their probability distributions are investigated.

We calculate the radial rainfall profile and 2D TCcentered rainfall spatial distribution to evaluate the rainfall structure reproduced by TCRM. To obtain the radial rainfall, we calculate the rainfall averaged over $25-\mathrm{km}$ radial annuli, and we present the radial rainfall profile averaged over three storm intensity categories: tropical storms (TS), category 1-2 hurricanes (CAT1-2), and category 3-5 hurricanes (CAT3-5). Two-dimensional TCcentered rainfall field can reveal asymmetric features of TC rainfall. The 2D TC-centered rainfall field is obtained by rotating the rainfall field so that the positive $y$ axis is aligned with the direction of TC motion. We present the 2D TC-centered rainfall field averaged over each of the three storm intensity categories.

In addition to rainfall features of individual events, we study the spatial and temporal variations of rainfall. We analyze the spatial distribution of annual rainfall distribution in the continental United States. The observed and simulated rainfall fields are first interpolated onto $0.25^{\circ} \times 0.25^{\circ}$ grid points in the continental United States and then averaged over the years 1999-2018 to obtain the distribution of the annual rainfall.

To quantitatively analyze the performance of TCRM on generating the spatial distribution of the average annual rainfall, the equitable threat score (ETS) is computed. ETS measures the ratio of grid points where the model results match with observations for a given threshold (Tuleya et al. 2007), and it can be written as

$$
\mathrm{ETS}=\left(H-H_{\text {random }}\right) /\left(F+O-H-H_{\text {random }}\right) .
$$

Parameters $F$ and $O$ are the numbers of grid points where the simulation and observation satisfy a specified threshold (e.g., greater than the $70 \%$ percentile of observed rainfall), respectively. Parameter $H$ is the number of grid points where both the simulation and observation meet the specified criteria. ETS has an advantage over the simpler threat score, as it removes the random prediction that meets the criteria by considering the random hitting denoted by $H_{\text {random, }}$

$$
H_{\text {random }}=F O /(F+O) .
$$

We calculate ETS for various threshold values and compare it across various model results (i.e., TCRM with various wind profile inputs).

The interannual variability of TC rainfall holds great importance in understanding TC rainfall climatology in a changing climate. The power dissipation index (PDI), which is a simplified version of PD and can be calculated by integrating the cube of maximum sustained wind over storm lifetime, has been used extensively to study the destructiveness of TCs (Emanuel 2005). This destructiveness measure, however, does not directly consider the effect of rainfall. Here we use a measure that considers the effect of "wet energy" released from TCs, or wet power dissipation (WPD), which is mathematically similar to PDI but integrates total rainfall instead of Vmax cube. Thus, WPD is simply the sum of STR over all storms in a given year. We analyze the annual variability of WPD to understand the capability of TCRM to capture the annual variability of TC rainfall climatology.

We are also interested in the potential application of TCRM in studying TC-generated flooding, where TCRM can provide simulated rainfall time series to drive hydrologic modeling. To investigate this potential, we exam TCRM's ability to capture the temporal evolution of rainfall and short-term rainfall extremes. Thus, time series of rainfall at the point of interest (POI) generated by TCRM and from Stage IV are extracted, with a time span from $24 \mathrm{~h}$ before the TC hit the POI to $24 \mathrm{~h}$ after (where the hitting point is defined as the time when the TC moves closest to the POI). The POI in this study is defined as any grid point (in the $1^{\circ} \times 1^{\circ}$ mesh) over the continental United States that has observed at least one time series of defined TC rainfall for at least $12 \mathrm{~h}$. In total, 7767 time series are selected for this analysis. Time series from different locations and storms are averaged to show the first-order features of TC rainfall time series structure. Statistics including the ratio of the maximum rainfall over the average rainfall, coefficient of variation, and hours of intermittence of rainfall are investigated.

\section{Results}

\section{a. Case studies}

Here we display the cumulative rainfall from three historical cases based on TCRM simulations with the $\mathrm{C} 15$ wind profile model and Stage IV observations (Fig. 1): Hurricanes Isaac (2012), Irene (2011), 
a

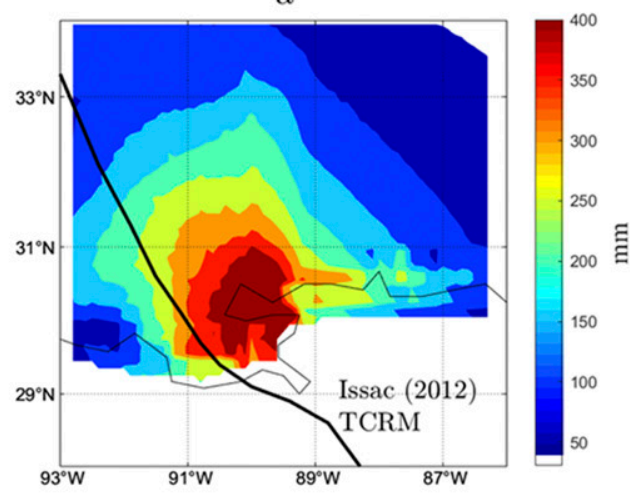

$\mathrm{C}$

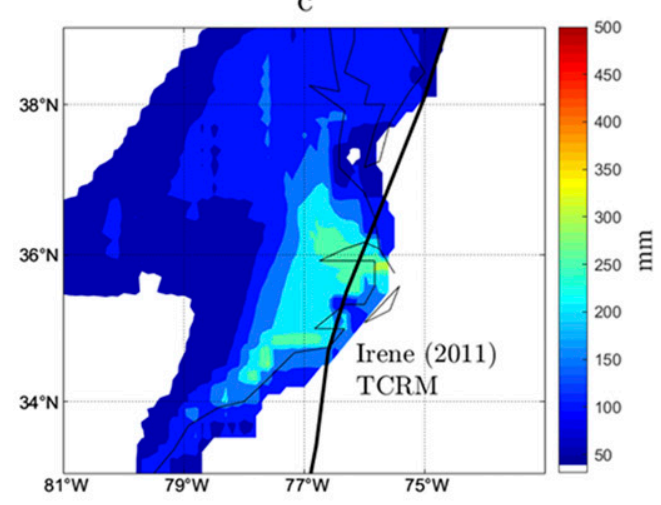

$\mathrm{e}$

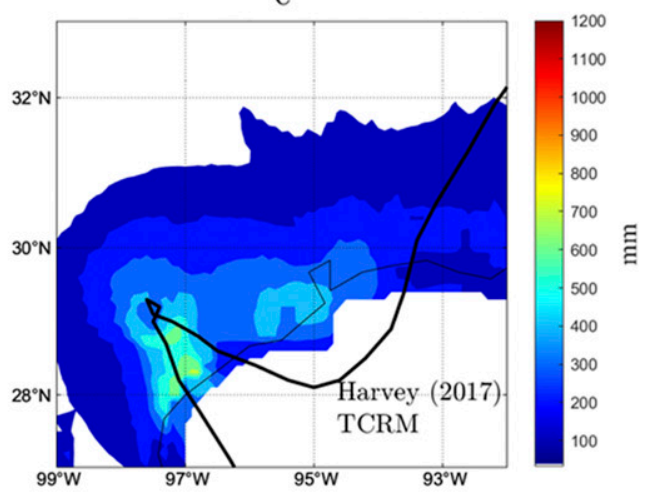

$\mathrm{b}$

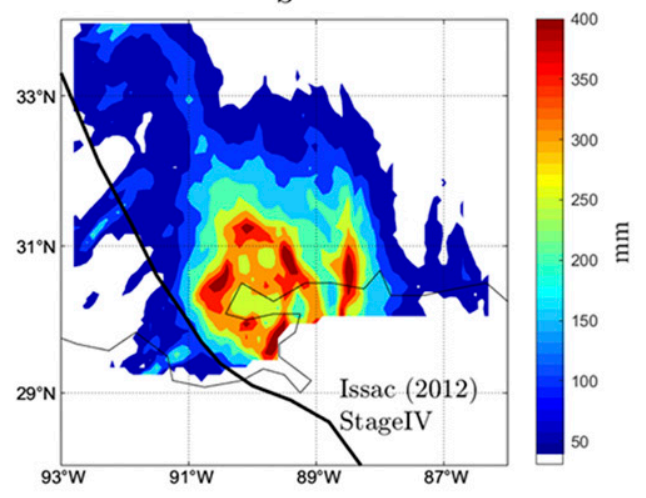

$\mathrm{d}$

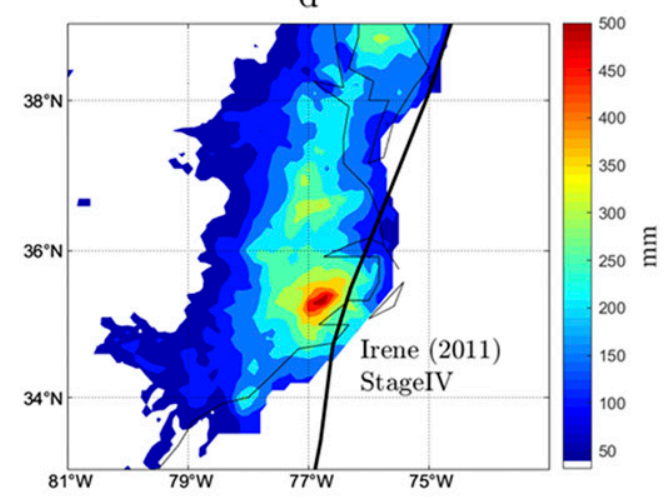

f

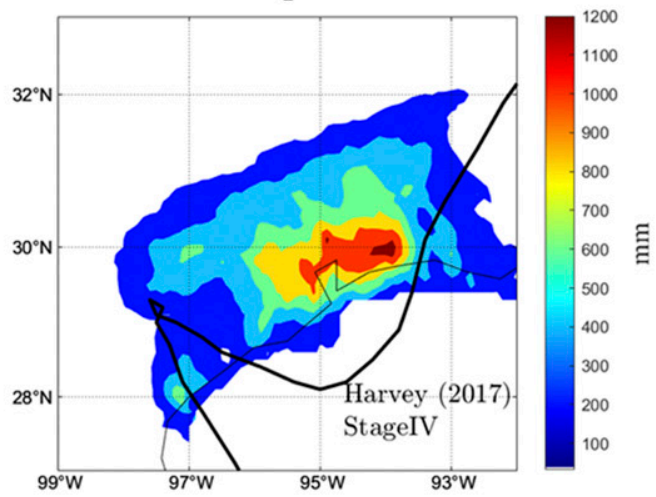

FIG. 1. Distributions of accumulated rainfall for three selected storms. (a) TCRM simulation for Hurricane Isaac (2012), (b) Stage IV observation for Hurricane Isaac (2012), (c) TCRM simulation for Hurricane Irene (2011), (d) Stage IV observation for Hurricane Irene (2011), (e) TCRM simulation for Hurricane Harvey (2017), and (f) Stage IV observation for Hurricane Harvey (2017). Solid black lines indicate the tracks of the storms.

and Harvey (2017). The three storms reflect a spectrum of model performance.

Isaac exemplifies a "satisfactory" simulation. TCRM generally captures both the magnitude and location of rainfall maximum. The discrepancy between simulation and Stage IV observation over Lake Pontchartrain $\left(30.18^{\circ} \mathrm{N}, 90.12^{\circ} \mathrm{W}\right)$ is likely due to the unsatisfactory representation of the drag coefficient in the model for the lake based on the $0.25^{\circ} \times 0.25^{\circ}$ surface roughness map, the uncertainties of observations over the lake, or both.

The simulation of Irene is less satisfactory. The TCRM simulation underestimates the rainfall at landfall and high latitudes. Irene went through extratropical 
transition at high latitudes (Liu and Smith 2016) while TCRM, focusing on the rainfall mechanisms of TCs with tropical features, lacks an explicit account of the effect of extratropical transition (as also discussed in $\mathrm{Lu}$ et al. 2018).

Harvey produced heavy rainfall around Houston. TCRM cannot reproduce this extreme. A possible explanation is that Harvey was interacting with a stationary front near Houston (Blake and Zelinsky 2018), which is beyond the ability of TCRM to capture.

Based on the examination of these and other storms, we found that TCRM performs relatively well in simulating the rainfall from TCs that have a coherent and compact structure and limited interaction with other meteorological systems. Performance of TCRM may be undermined for TCs that move to higher latitudes or further inland, when they tend to lose their compact structure and tropical features and become more likely affected by other weather systems.

\section{b. Storm total rainfall}

To evaluate the performance of TCRM more generally, we first analyze the statistics of STR. All four wind profile models (H80, E04, ER11, and C15) are applied; TCRM is denoted as H80-TCRM, E04TCRM, ER11-TCRM, and C15-TCRM to indicate the specific wind model used. From the comparison between simulated and observed STR values for all TCs from 1999 to 2018 (Fig. 2), it is found that among the four wind profiles, $\mathrm{C} 15$ renders the highest correlation and the lowest bias compared to the SRO. RCLIPER produces simulations with neither higher correlation coefficient nor lower bias than C15-TCRM, even though it was developed to represent TC rainfall statistics based on the TRMM observations. E04 renders a large negative bias. A bit unexpectedly based on the previous study (Lu et al. 2018), H80-TCRM has the lowest correlation with the SRO and the largest bias. Generally, TCRM underestimates STR (i.e., negative bias), especially for extremes. One explanation is that TCRM slightly underestimate the rainfall at large radii (shown in the next section). However, H80TCRM has a significant positive bias. Two reasons are possible: 1) H80-TCRM overestimates inner core rainfall compared to other wind profile models; and 2) it also overestimates outer radii rainfall for relatively weak, tropical storms. Both features are apparent in the rainfall radial profile shown in the next section. The comparison between the probabilistic distribution function (PDF) of the simulation residuals among the models is similar in shape for ER11-TCRM, C15-TCRM, and RCLIPER, with C15-TCRM producing higher density around zero residual (Fig. 2f).
E04-TCRM biases toward underestimating and H80 biases toward overestimating the STR.

We further compare the probability distribution of STR from TCRM and SRO. A quantile-quantile plot (QQplot) is used to examine the model's performance of reproducing the correct statistical distribution of STR, and the behavior in the tail region is of particular interest from risk perspectives. As shown in Figs. 3a-e of the QQplot of simulated and observed STR, for all wind profile inputs, the probability distribution of STR generated by TCRM has a heavier tail than that from SRO. Note that although TCRM, except H80TCRM, tends to underestimate STR, it is not in conflict for TCRM to generate a STR distribution with a heavier tail than that from SRO, as extremes are defined relative to the shape of the probability distribution of the quantity rather than its absolute values. In comparison, RCLIPER produces a STR distribution that is closer to SRO but with a lighter tail. The STR distributions are also compared with the theoretical exponential distribution in Figs. $3 \mathrm{f}-\mathrm{h}$. It is found that both TCRM (using C15-TCRM as an example) and RCLIPER generate a distribution that decreases faster (i.e., has a lighter tail) than the exponential distribution, similar to SRO.

\section{c. TC rainfall structure}

Rainfall radial profiles of the NA TCs produced by various TCRM models and obtained from SRO for three TC sets: TS, CAT1-2 storms, and CAT3-5 storms are compared to show the model performance in capturing TC rainfall structure (Fig. 4). In all cases, TCRM overestimates the rainfall in the inner core region of the storm compared to SRO. RCLIPER simulation for the inner region compares better with SRO for CAT1-2 and CAT3-5, possibly because RCLIPER was developed based on the SRO statistics on TC rainfall profiles. Although SRO has been reported to underestimate extreme rainfall (Berg et al. 2006), the large discrepancy between the simulation and SRO is likely induced also by model limitations.

TCRM's overestimation of rainfall around and within the RMW may be caused by the model's oversensitivity to the effect of the large radial gradient of the wind in the region. This overestimation, however, is not evident in the estimation of the areal integral quantity STR, as the inner core region is much smaller in area than the outer radii region. Overestimation by TCRM also has a relatively small impact on rainfall risk assessment focusing on total rainfall at a particular location. Because the likelihood and possible duration of the location of interest being affected by the inner core region of any approaching storm is relatively small (proportional to 

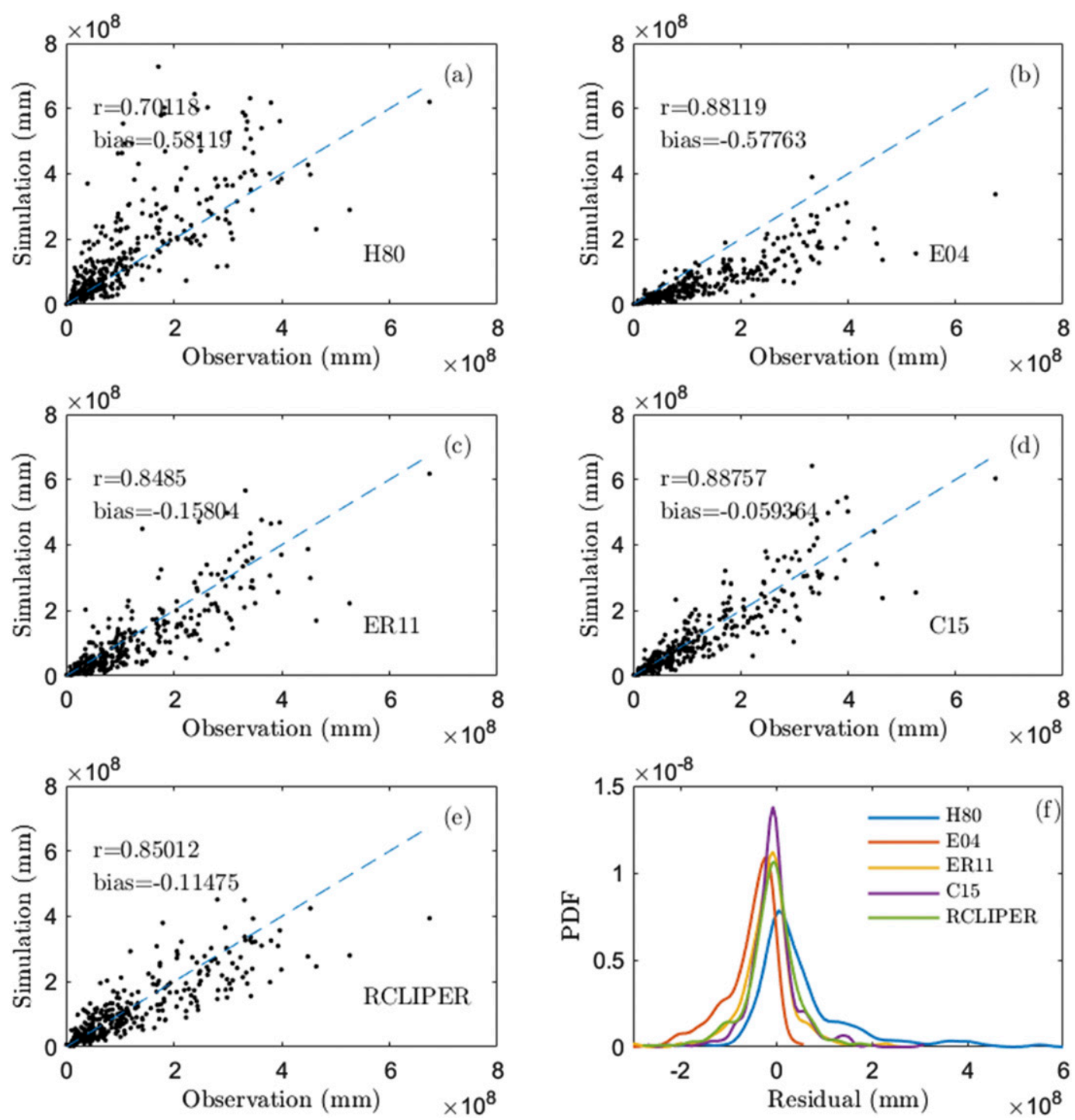

FIG. 2. Correlation of simulated and observed STR of North Atlantic TCs from 1999 to 2018. Five models are applied to the simulation: (a) H80-TCRM, (b) E04-TCRM, (c) ER11-TCRM, (d) C15-TCRM, and (e) RCLIPER. (f) PDF of simulation residual (simulation - observation) for the five models.

the radius), the contribution from large radii dominates the total rainfall statistics across all approaching storms.

At outer radii, both E04-TCRM and ER11-TCRM underestimate TC rainfall. H80-TCRM significantly overestimate outer radii rainfall for TS, slightly overestimate rainfall for CAT 1-2, and underestimate rainfall for CAT 3-5. RCLIPER simulation compares relatively well with SRO for CAT 1-2 and CAT 3-5 but not as well for TSs. C15-TCRM compares relatively well with SRO, with a slight underestimation of rainfall for TS and CAT 1-2 in 200-400 km radii. This explains why C15-TCRM-estimated STR compares better with observed STR, as discussed above. The slight underestimation of the rainfall profile in the outer regions by
C15-TCRM may be related to the model's limitation in capturing some of the extreme rainfall events caused by TCs interacting with other systems (e.g., Harvey) or undergoing extratropical transition.

To study the asymmetric feature of the TC rainfall structure, we examine the 2D TC-centered rainfall distribution, with positive $y$ axis oriented toward the direction of $\mathrm{TC}$ motion, in a $5^{\circ} \times 5^{\circ}$ domain using C15TCRM as an example (Fig. 5). C15-TCRM reproduces a relatively satisfactory radial extent of TC rainfall and can reproduce the observed forward to forward-right enhancement of rainfall induced by TC motion (Lonfat et al. 2004; Liu et al. 2018). The center of heavy rainfall, however, is located closer to the $y$ axis in the simulation 

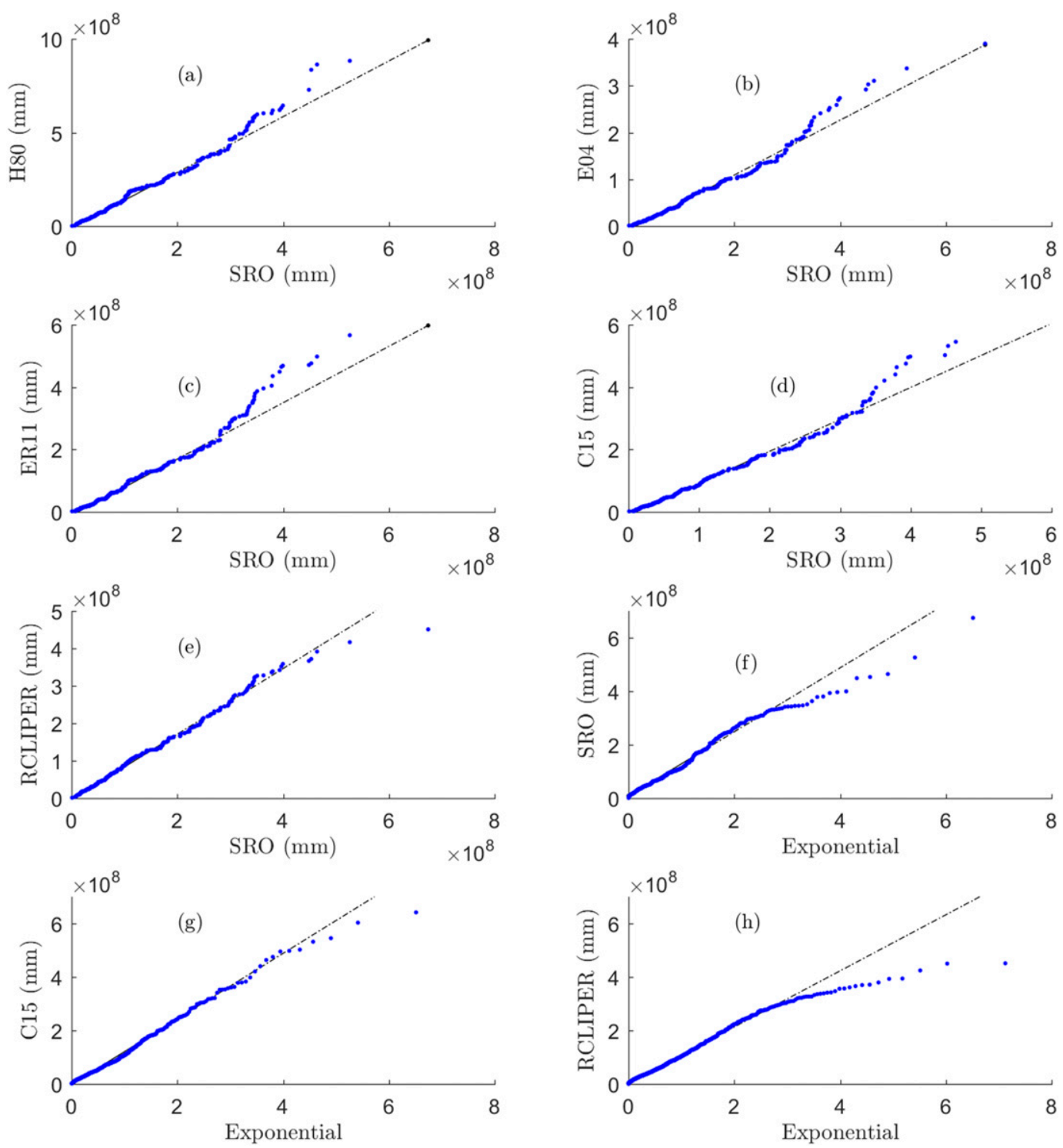

FIG. 3. QQplot of simulated and observed STR of North Atlantic TCs from 1999 to 2018. (a) H80-TCRM against SRO, (b) E04-TCRM against SRO, (c) ER11-TCRM against SRO, (d) C15-TCRM against SRO, (e) RCLIPER against SRO, (f) SRO against theoretical exponential distribution, (g) C15-TCRM against theoretical exponential distribution, and (h) RCLIPER against theoretical exponential distribution.

while the observed maximum rainfall is farther away from the $y$ axis to the right. The shift of rainfall maxima is more obvious for TS and CAT1-2 TCs than for CAT3-5 TCs. The figures (Figs. 5g-1) showing the ratio between the asymmetric rainfall and the radially averaged symmetric rainfall also indicate that the asymmetric rainfall in the C15-TCRM simulation is closer to the TC center. The asymmetric features of the rainfall in the observation may be influenced by TC rainbands distant from the TC center, which TCRM cannot capture. TCRM coupling with other wind profile models produces less satisfactory rainfall structures, with the simulated extent of rainfall smaller than that from SRO (not shown).

\section{d. TC rainfall distribution on continental United States}

Spatial distributions of the annual TC rainfall averaged from 1999 to 2018 in SRO and simulation are compared to understand the performance of TCRMs in reproducing TC rainfall climatology patterns (Fig. 6). Among various models, C15-TCRM produces the most plausible result, with a high correlation with SRO and comparable (slightly higher) amounts of rainfall on the 

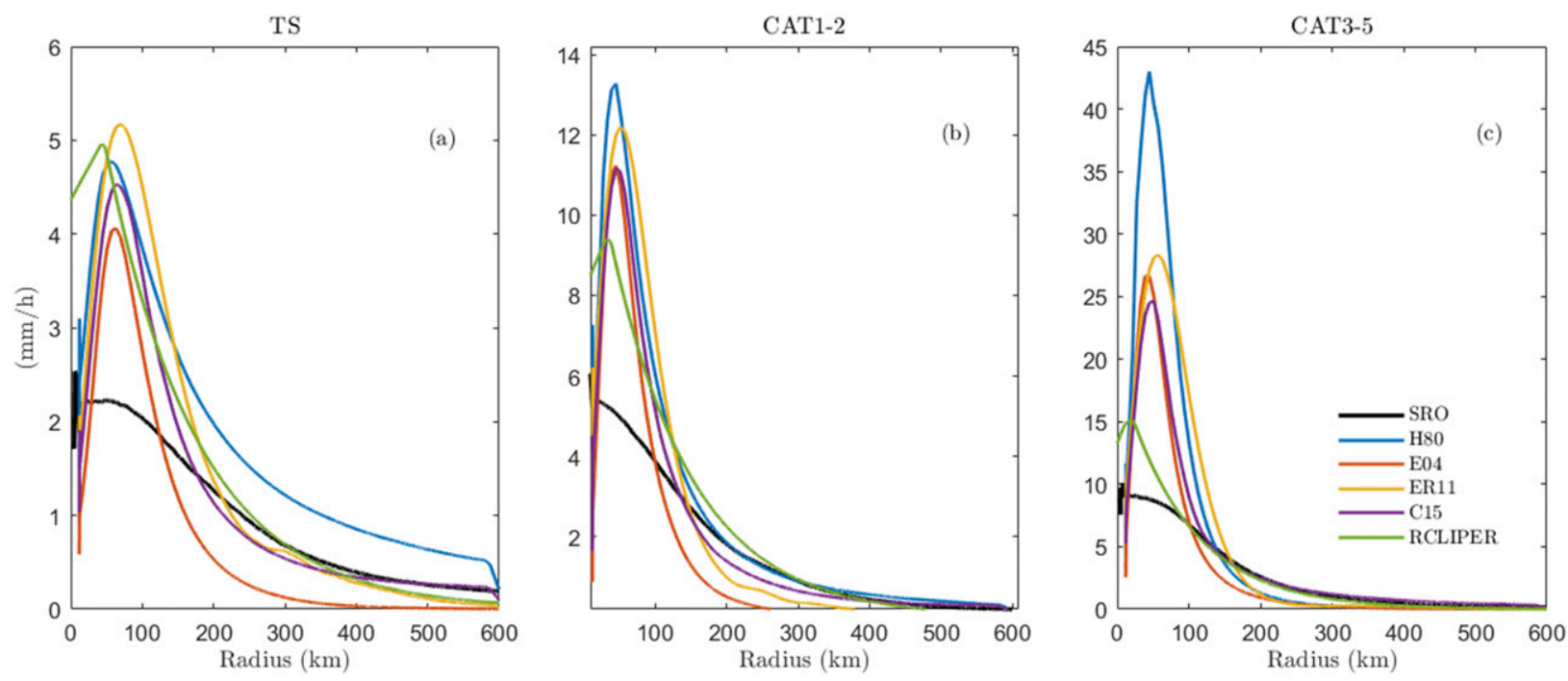

FIG. 4. Radial profile of observed and simulated TC rainfall. (a) TSs, (b) category 1-2 hurricanes, (c) category 3-5 hurricanes.

East Coast, Gulf Coast, and the Appalachians, although the model underestimates the inland extend of TC rainfall and overestimates the rainfall in coastal Florida. One possible explanation of the underestimation of inland rainfall is that the model is formulated to associate rainfall with the vertical velocity related to the secondary circulation of the TC, while TC rainfall can also be produced by stratified clouds or local convections. After the TC moves on land for a while, the compact structure of the TC is likely destroyed by the surface friction so the vertical velocity or the rainfall related to the secondary circulation becomes rather weak. H80-TCRM significantly overestimates rainfall in coastal regions as well as the Appalachians. ER11-TCRM renders the highest correlation coefficient, but it significantly underestimates rainfall on the East and Gulf Coasts as well as the Appalachians. RCLIPER significantly underestimates the rainfall on land, simply because it takes only the intensity of the storms into account and represents neither the impact of surface roughness nor topographical effects, which can significantly enhance the rainfall.

Figure 7 shows the ETS values calculated based on the rainfall distribution shown in Fig. 6, as well as the fitted probability distribution of annual rainfall at the grid scale. As indicated by the ETS values, the models have similar behaviors for low rainfall thresholds, where H80-TCRM and C15-TCRM outperform E04-TCRM and ER11-TCRM. For high rainfall thresholds, C15-TCRM still shows considerable modeling ability while the performance of H80-TCRM (and E04-TCRM) drops quickly. The comparison of the PDF of simulated and observed annual average rainfall shows that the probability of annual averaged TC precipitation exceeding
$150 \mathrm{~mm}$ is larger in the simulation than in SRO. Thus, TCRM tends to overestimate heavy rainfall compared to SRO, corresponding to the slight overestimation of rainfall in coastal regions as noted in Fig. 6. As mentioned before, underestimation of heavy rainfall in SRO can be a reason for this discrepancy. However, it is possible that TCRM is too sensitive to the drag coefficient change as well as the topographic effects.

To further investigate the spatial variation of TC rainfall, simulated (C15-TCRM) and observed annual TC rainfall at latitudes higher than $38^{\circ} \mathrm{N}$ are compared to evaluate the model performance in high latitudes (Fig. 8). The simulated rainfall at latitudes higher than $38^{\circ} \mathrm{N}$ is significantly smaller than SRO, and the correlation between the simulation and SRO is significantly weaker compared to the correlation for the entire continental United States. The lower model performance for high latitudes is likely because TCRM cannot produce the complex rainfall features of extratropical transited TCs or the TCs influenced by strong shears in mid and high latitudes, as mentioned above. Indeed, Lu et al. (2018) compared the TCRM simulation with WRF simulation for two extratropical transition cases: Hurricane Isabel (2002) and Hurricane Irene (2011). They found that for Hurricane Isabel WRF produced rainfall over $75 \mathrm{~mm}$ in West Virginia, while TCRM can produce rainfall only around $40 \mathrm{~mm}$ there; for Hurricane Irene, the rainfall in higher latitude from WRF is more asymmetric and concentrated to the left of the track, while rainfall in TCRM is more symmetric. In both cases, the discrepancy was found during the time when the TC was going through extratropical transition. Though TCRM has a representation of the 

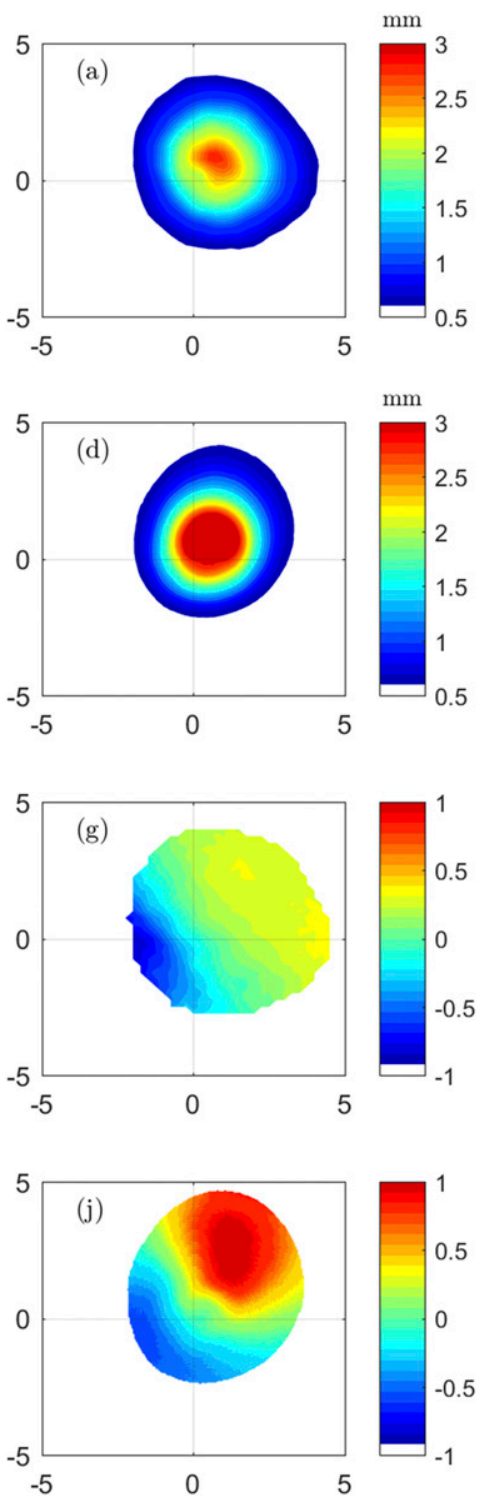

FIG. 5. TC-centered rainfall distribution: (a)-(c) observation for TS, CAT1-2, CAT3-5, respectively; (d)-(f) C15-TCRM simulation for TS, CAT1-2, CAT3-5, respectively; (g)-(i) ratio between asymmetric (calculated by subtracting radially averaged symmetric rainfall from the total rainfall) and symmetric rainfall components in observation for TS, CAT1-2, and CAT3-5, respectively; and (j)-(1) ratio between asymmetric and symmetric rainfall components in C15-TCRM simulation for TS, CAT1-2, and CAT3-5, respectively.

"baroclinic effect" on rainfall, this representation is deduced based on the averaged effect of shear on TCs (Lu et al. 2018) while extratropical transition of TCs is initiated with asymmetric features. It is of interest and importance for future research to dynamically or statistically capture the rainfall of extratropical transited storms, as some recent research argues that more TCs may make landfall in higher latitudes under future climate conditions (Liu et al. 2018).

Although we have used SRO to evaluate the model performance in capturing large-scale rainfall distributions, SRO has a relatively coarse resolution $\left(0.25^{\circ} \times 0.25^{\circ}\right)$.
Here we zoom into specific areas- the Gulf of Mexico, the Carolinas, and Florida Peninsula-to further investigate the performance of TCRM in revealing detailed rainfall patterns of accumulated rainfall of 36 landfalling TCs (listed in Table 1) in these regions using the Stage IV observation (4-km horizontal resolution) in addition to SRO (Fig. 9). For the Gulf of Mexico, Stage IV and SRO observations have similar rainfall extending inland. TCRM is able to reproduce the rainfall gradient near the coast although it produces fewer rainfall-covered areas further inland. Another feature worth noticing is that Stage IV observes a local maximum of rainfall at the coast of Apalachee Bay 

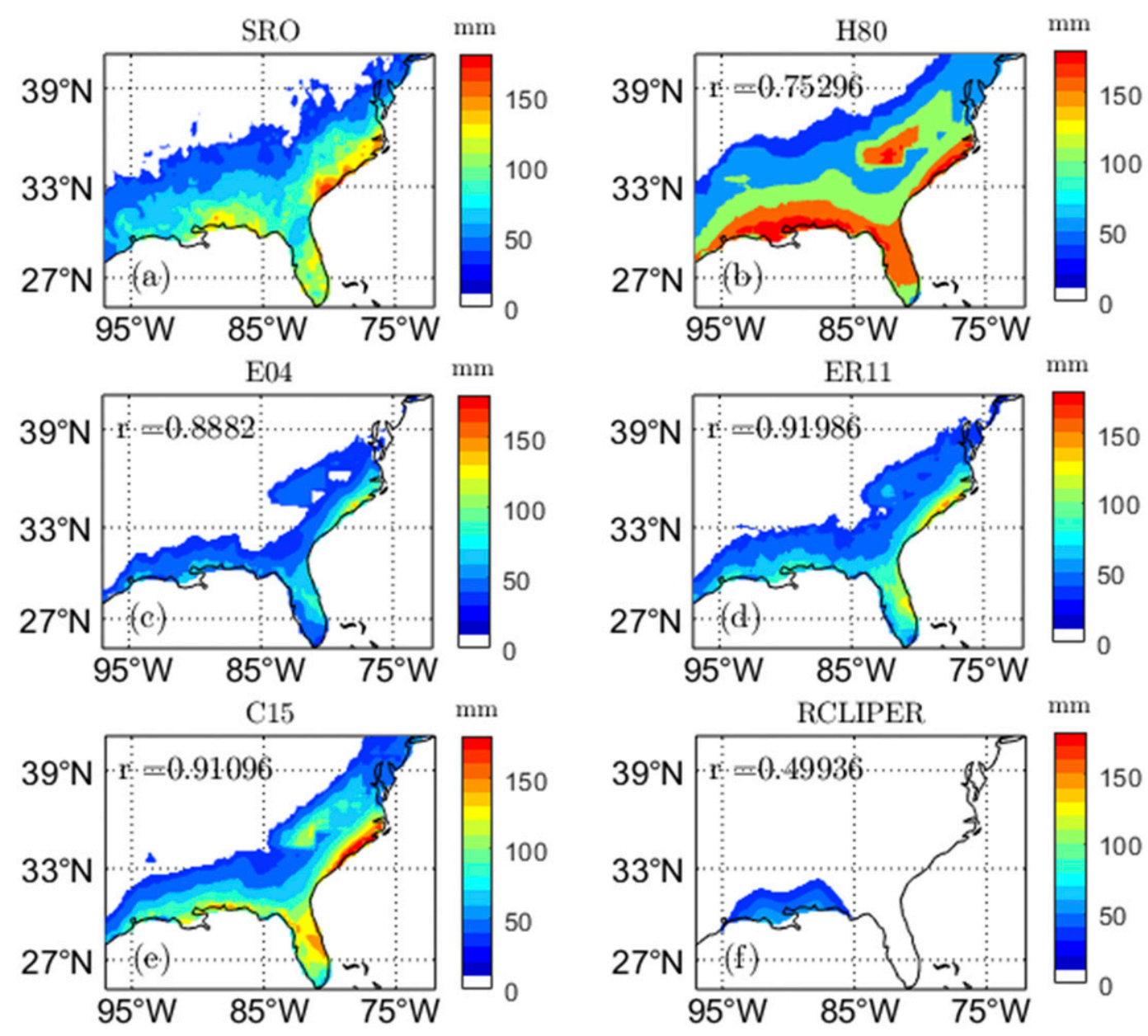

FIG. 6. Distribution of annual averaged TC rainfall $(\mathrm{mm})$ in the continental United States from observation and simulation: (a) SRO, (b) H80-TCRM simulation, (c) E04-TCRM simulation, (d) ER11-TCRM simulation, (e) C15TCRM simulation, and (f) RCLIPER simulation. Annual averaged rainfall less than $30 \mathrm{~mm}$ is masked. Correlation coefficient of simulated rainfall field and observed rainfall field is noted at the top of each figure.

$\left(30^{\circ} \mathrm{N}, 84^{\circ} \mathrm{W}\right)$, which SRO fails to observe. TCRM is able to capture this maximum although it underestimates the affected area. For the Carolinas, TCRM, Stage IV, and SRO all show large rainfall areas along the coast and a maximum north of the North Carolina near the mouth of the Chesapeake Bay $\left(37^{\circ} \mathrm{N}, 77^{\circ} \mathrm{W}\right)$, although the magnitude is much larger in Stage IV than in TCRM or SRO. At the Appalachian Mountains, Stage IV observes a maximum total rainfall exceeding $1000 \mathrm{~mm}$ around $\left(35^{\circ} \mathrm{N}, 83^{\circ} \mathrm{W}\right)$, while SRO cannot capture this significant maximum. TCRM captures this maximum but with a smaller magnitude $(700 \mathrm{~mm})$. For the Florida Peninsula, TCRM slightly overestimates the rainfall maximum in lower east Florida $\left(28^{\circ} \mathrm{N}\right.$, $81^{\circ} \mathrm{W}$ ) and underestimates the rainfall maximum around Jacksonville $\left(30^{\circ} \mathrm{N}, 81.5^{\circ} \mathrm{W}\right)$, compared to Stage IV. SRO has lower rainfall near coastlines compared to Stage IV and TCRM, but it observes heavier rainfall in the center of Florida $\left(28^{\circ} \mathrm{N}, 81.2^{\circ} \mathrm{W}\right)$. These detailed comparisons indicate that TCRM performs relatively well in reproducing landfalling TC rainfall patterns including maximums (in mid- and low latitudes), but the magnitudes of the rainfall maximums may be to some extent underestimated for mountainous regions compared to the Stage IV observation (even though they appear to be slightly overestimated compared to the SRO).

\section{e. Interannual variability of TC rainfall}

To understand the ability and uncertainty of TCRM to reproduce the interannual variability of TC rainfall, we compare the WPD defined in section 2 in the simulation and SRO. As shown in Fig. 10, TCRM performs reasonably well in simulating the interannual variability of WPD. Among the four TCRM models, C15-TCRM matches relatively well with $\mathrm{SRO}$ with a high correlation 

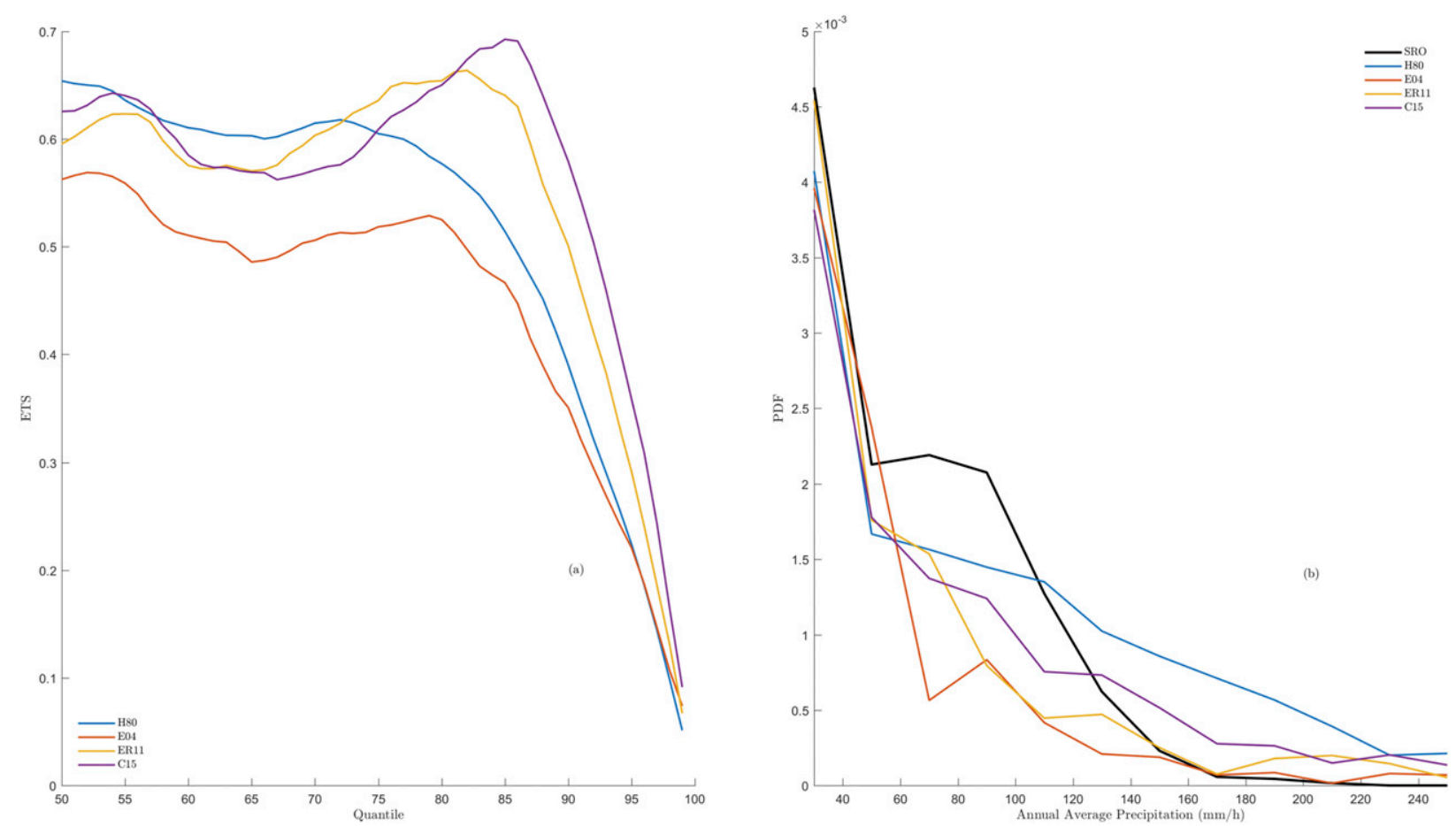

FIG. 7. Comparison of annual average precipitation probability distribution. (a) ETS score of each coupled TCRM model. The $x$ axis is the quantiles of observed annual averaged rainfall in the continental United States, and the $y$ axis stands for the ETS score based on the simulation for each given quantile threshold. (b) PDF of annual averaged rainfall in each grid point.

coefficient; the temporal average of WPD from the C15TCRM simulation is closest to the observed mean WPD, indicating that C15-TCRM has the least bias.

It is noted that the annual variability of WPD is related to the annual number of TCs and the PDI. To better analyze the capability of TCRM in revealing the interannual variabilities, we analyze the WPD scaled by the annual TC number and PDI (shown in Fig. 10a). Figure 11a compares the observed and simulated WPD scaled by the annual TC number, which may be interpreted as the average precipitation ability of the storms in a given year. The scaled WPD has a quasi-biannual-period feature, which TCRM reproduces. Among the models, RCLIPER has the highest correlation coefficient, C15-TCRM has the lowest mean bias, and H80-TCRM has the lowest correlation coefficient with SRO. Figure 11b shows the WPD scaled by the PDI, which may be interpreted as showing, for a unit of "dry energy" released from a storm, how much "wet energy" can be released. All models perform reasonably well in this metric, with C15-TCRM having the lowest mean bias. A considerable peak of the scaled WPD in 2013 is noted, a feature that all models can capture and for which C15TCRM renders the best match. This peak could be caused by the fact that NA TCs in 2013 spend more of their lifetimes over the open ocean than TCs from other years and thus were "wetter."

\section{f. Temporal evolution of TC rainfall}

Although it is argued above that the bias on the radial distribution and the asymmetric structure of TC rainfall cause relatively small effects on the estimation of storm
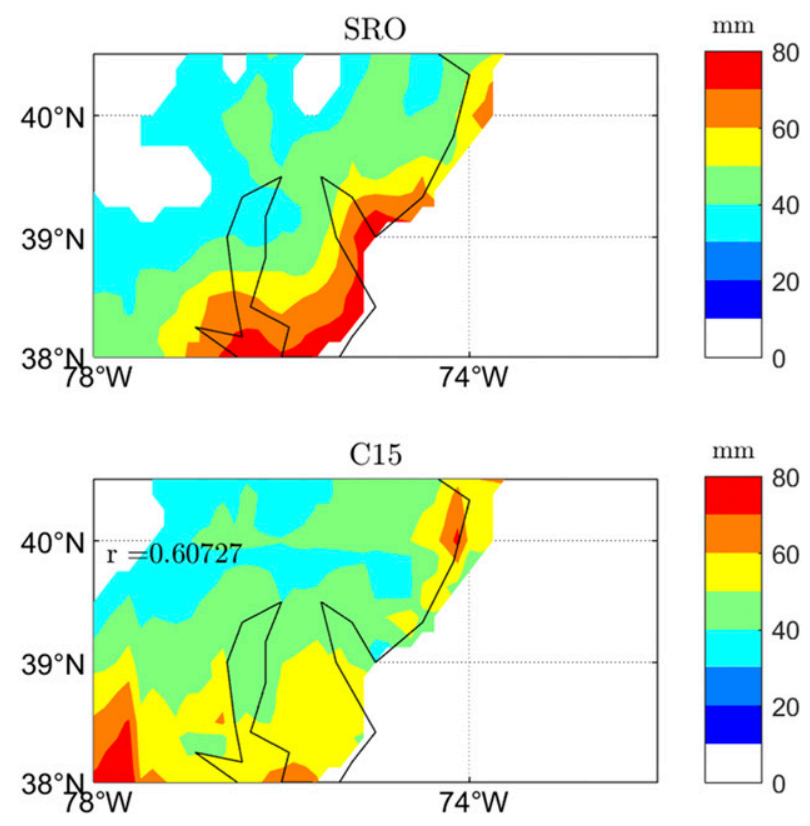

FIG. 8. As in Fig. 6, but only for latitudes higher than $38^{\circ} \mathrm{N}$. 

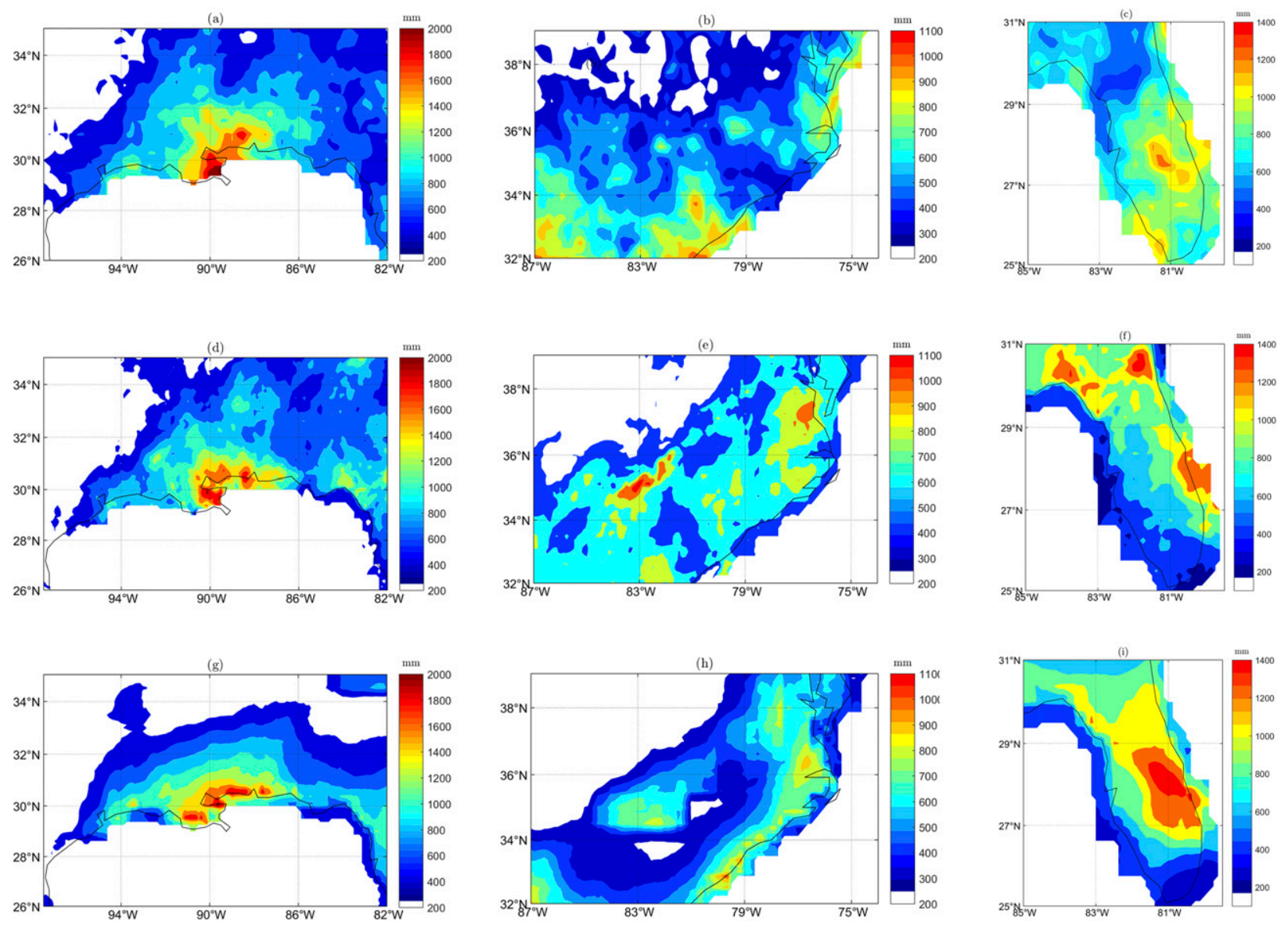

FIG. 9. Accumulated rainfall (mm) for 36 landfalling TCs from 2002 to 2012. (a),(d),(g) SRO, Stage IV observation, and C15-TCRM simulation for TCs that made landfall at the Gulf of Mexico, respectively; (b),(e),(h) SRO, Stage IV observation, and C15-TCRM simulation for TCs that impacted the Carolinas and the Appalachian Mountains, respectively; and (c),(f),(i) SRO, Stage IV observation, and C15-TCRM simulation for TCs that impacted the Florida Peninsula, respectively.

total rainfall, they may influence the temporal evolution of rainfall simulated for a given geographic location, which may further jeopardize the credibility of TCRM when coupled with hydrologic models to investigate flooding. In this section, we apply the Stage IV observation to study TCRM (C15-TCRM)-modeled TC rainfall time series. We interpolate both Stage IV and simulation datasets to a $1^{\circ} \times 1^{\circ}$ horizontal resolution, to average out local effects. Average rainfall time series from 7767 samples (each within $24 \mathrm{~h}$ before and $24 \mathrm{~h}$ after passing a POI) from the simulation and Stage IV observation for the 36 U.S. landfalling TCs from 2002 to 2012 (listed in Table 1) are compared (Fig. 12). TCRM reproduces the overall features of rainfall time series relatively well compared to the Stage IV observation, with the rainfall continuously increasing when the TC approaches the POI and decreasing when the TC moves away from the POI. However, it is noticeable that the peak rainfall from
Stage IV observation shifts several hours earlier than that from the simulation, and the magnitude of the peak is lower in the Stage IV observation. Stage IV observation on average has a larger (smaller) rainfall rate than TCRM before (after) the time when the storm hits the POI. Rainfall at the TC center is much larger in the simulation (Figs. 4 and 5); thus, the temporal peak (averaged over time series at all POIs) is higher in the simulation than in Stage IV. One possible explanation of the time lag of peak rainfall is that the peak rainfall in the observation can be induced by rainbands that propagate outward from center of the storm and hit the POI earlier than the center of the storm. TCRM cannot capture this feature as it does not have a representation of rainbands, and the peak rainfall in the model usually occurs when the TC center approaches the POI. This time lag and overestimation of the peak in the simulation may be important uncertainties to consider when using 

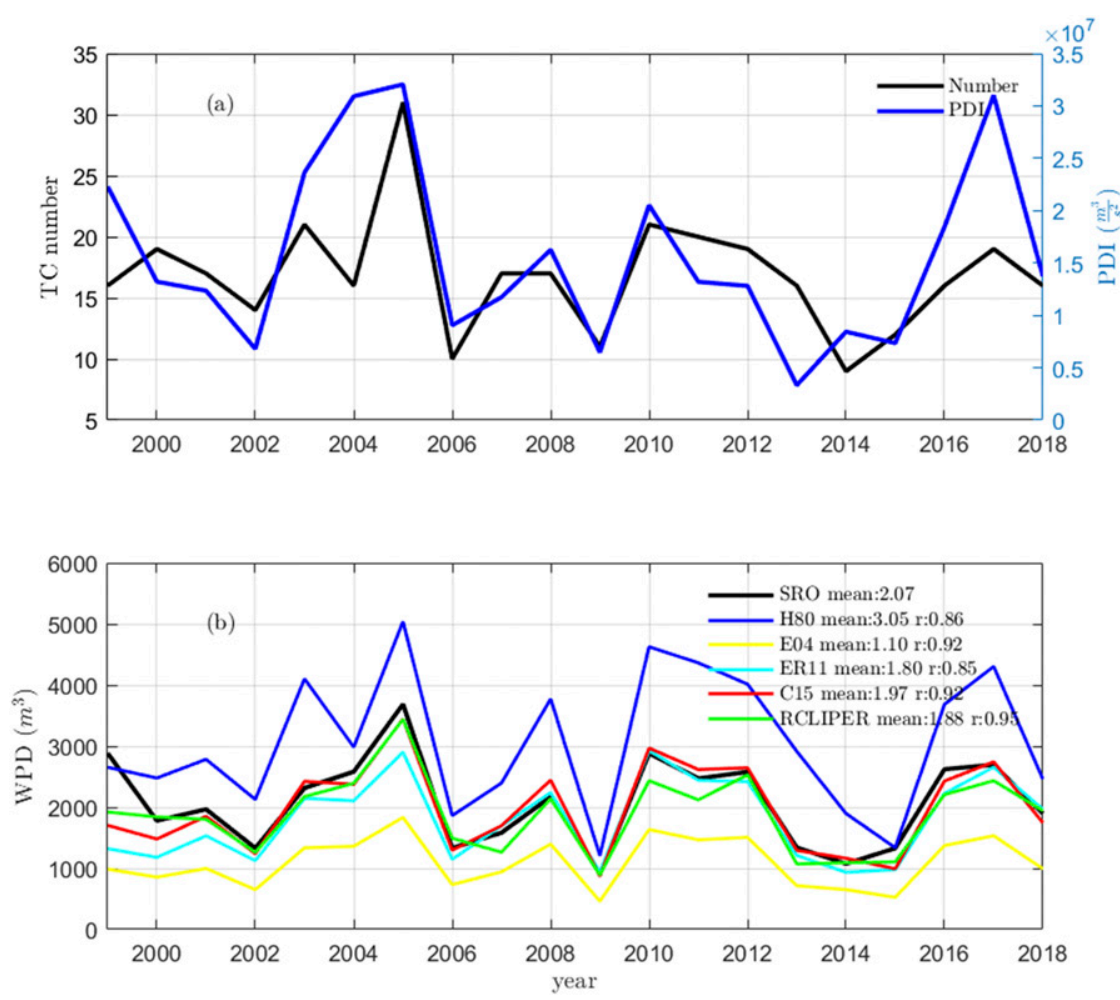

FIG. 10. Interannual variability of North Atlantic tropical cyclones. (a) Observed annual number and PDI of NA TCs; (b) observed and simulated annual WPD. Annual mean WPD and correlation coefficients between simulated and observed WPD are noted on the panel.

TCRM to study rainfall and surge compound flooding from TCs (Gori et al. 2020).

Besides the heavy amount of total rainfall TCs can produce, the risk of short-term heavy rainfall is also critical for TC rainfall risk assessment. Following Langousis and Veneziano (2009b), we compute the ratio between maximum 1-h rainfall and total rainfall and study its probability distribution. The comparison of PDF of the ratio from the Stage IV observation and simulation in Fig. 13a indicates that more rainfall events with considerable amounts of rainfall dumped in the hourly time scale occur in Stage IV; in the simulation, the short-term heavy rainfall is less common. TCs are convective systems, and TC rainfall can be generated from single convective cells whose magnitudes are relatively random statistically. However, TCRM is developed assuming an averaged boundary layer flow, filtering out the convective effect that may produce peak rainfall. The QQplot in Fig. 13b indicates that the distribution of the ratio from the simulation has a heavier tail than that from Stage IV. Relatively fewer samples of simulated ratios occur in the intermediate rainfall region in the simulation. Also, the POI spends most of its time far away from the storm center during a TC event, receiving most of the time relatively little or no rainfall. When the TC center approaches the POI, the overestimation of rainfall in the TC center results in an overestimated rainfall peak at the POI. The combined effects yield the heavier tail of the distribution of the ratio in Fig. 13b.

The limitation of the model in capturing short-term extremes can be seen more clearly by analyzing the hours of intermittence of rainfall, which is defined as hours of no rain. Figure 14a shows that the observed rainfall generally has fewer intermittent hours than the simulation because the convection can happen in any 1-h period, even when TC is not yet very close to the POI, leading to a higher probability of more raining hours in a time series. However, TCRM can produce rainfall at the POI only when the POI is relatively close to the TC center. Figure 14b also show a higher possibility of obtaining a high coefficient of variation (COV) of the rainfall time series in the Stage IV observation, indicating that the observed TC rainfall is much "noisier" than the simulated rainfall. The relative smoothness of the simulated time series is also a consequence of the lack of representation of the small-scale convection in TCRM.

Since TCRM is developed to efficiently assess TC rainfall risk, it may not be computationally efficient and 

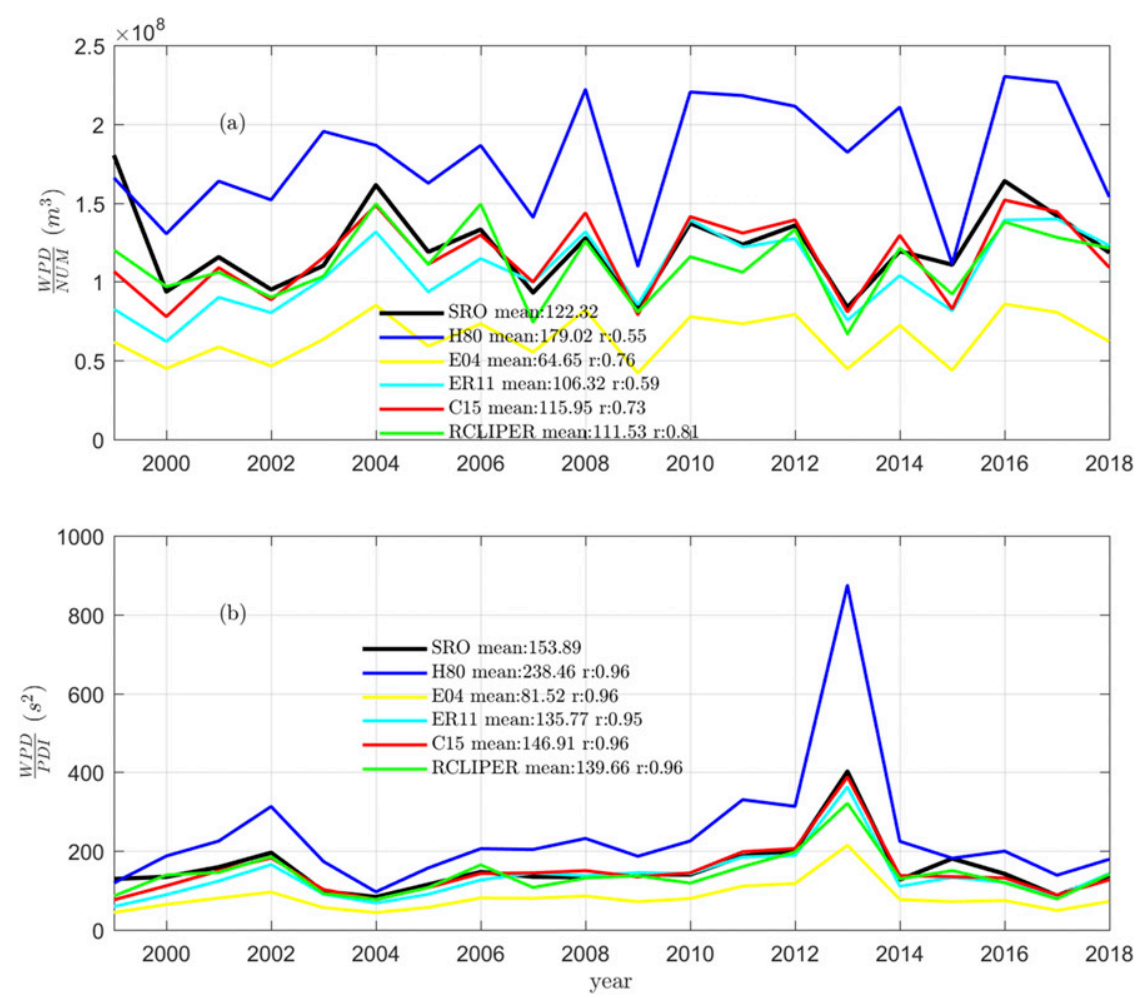

FIG. 11. Annual variability of scaled WPD. (a) WPD scaled by annual TC number; (b) WPD scaled by annual PDI. Annual mean scaled WPD and correlation coefficients between simulated and observed scaled WPD are noted on each panel.

physically feasible to capture isolated rainbands. Langousis and Veneziano (2009a) proposed a method of statistically modeling the ratio between the maximum rainfall and the average rainfall to analyze the risk of short-term extreme rainfall. This approach may be sufficient in supporting the analysis of the probability distribution of peak rainfall, yet the desired rainfall time series from TCs as input for hydrologic modeling cannot be obtained by such a method. Previous research proposed several stochastic models of rainfall time series (Rodríguez-Iturbe et al. 1987); however, none was specially designed for TC events, which can be characterized by storm characteristics such as track and intensity. Future efforts should focus on applying stochastic modeling techniques to better represent the temporal evolution of TC rainfall and couple such models with TCRM to assess short-term extreme rainfall hazard from TCs.

\section{Discussion}

\section{a. Sensitivity to simulation resolution}

In the previous sections, we ran TCRM with a horizontal resolution of $0.05^{\circ} \times 0.05^{\circ}$. Here, we briefly discuss the possible influence on the results of the simulation resolution. Figure 15 shows simulated TC-centered rainfall distribution similar to Fig. 5, but with a simulation resolution of $0.25^{\circ} \times 0.25^{\circ}$ and $0.5^{\circ} \times 0.5^{\circ}$; Fig. 16 shows the difference between the simulations with the coarser resolutions and the fine grid simulation. The results

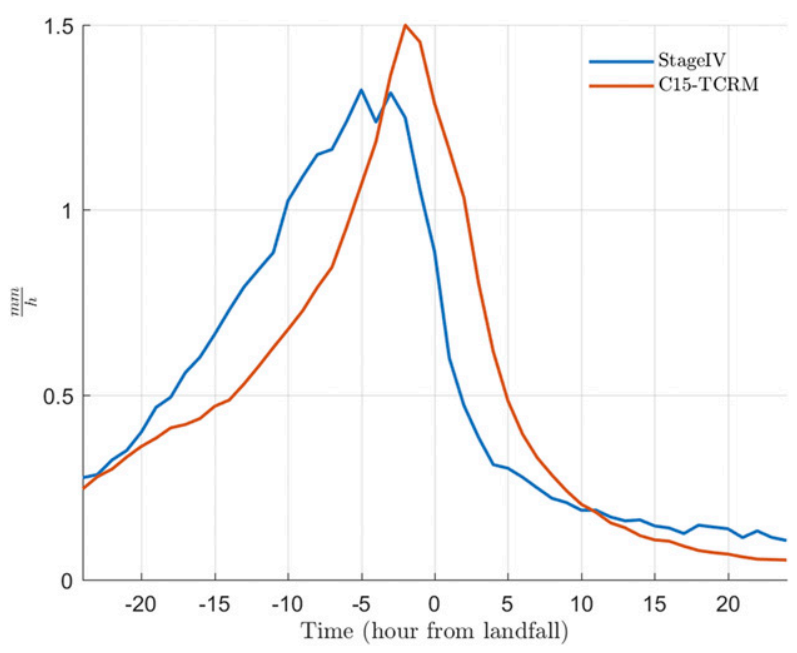

FIG. 12. Averaged time series of TC rainfall from $24 \mathrm{~h}$ prior to the nearest time to POI to $24 \mathrm{~h}$ after. 

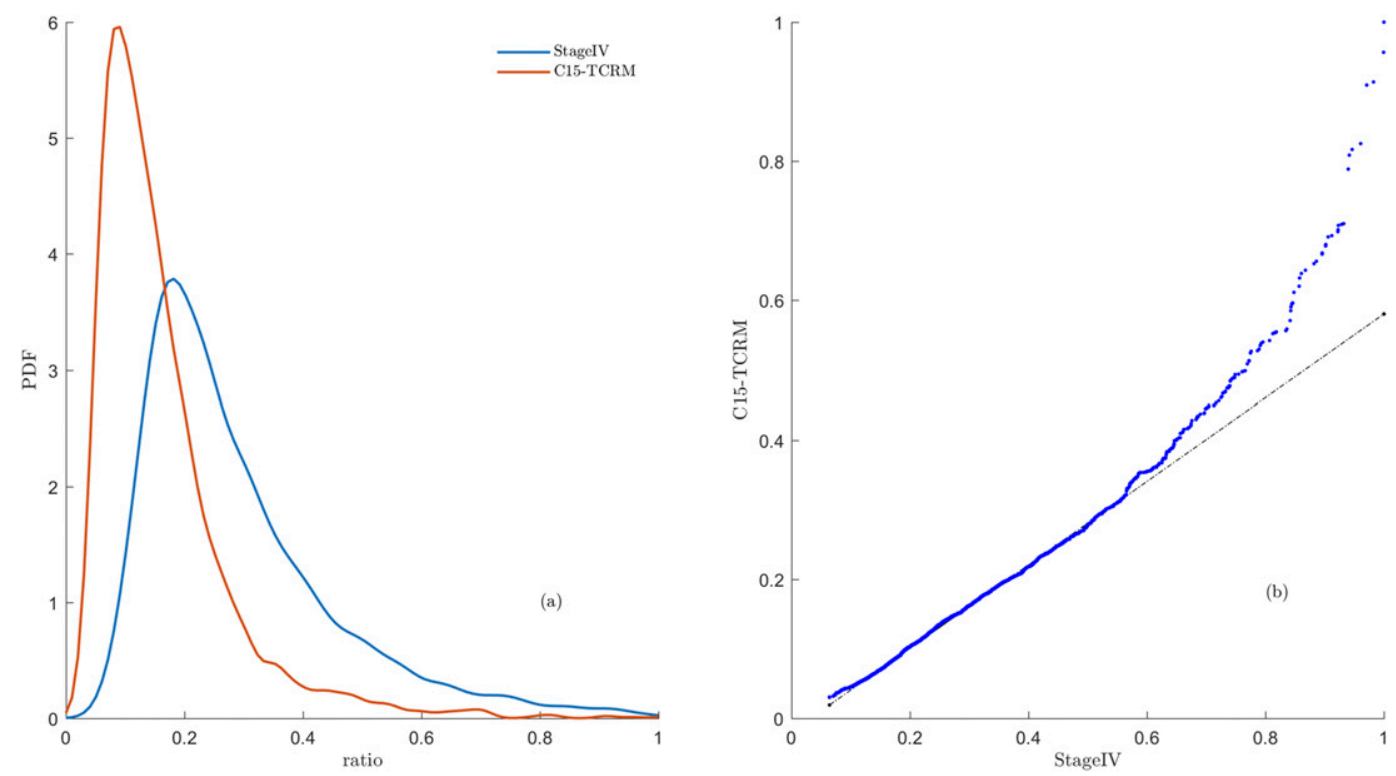

FIG. 13. Comparison of simulated and observed ratio between maximum rainfall and total rainfall: (a) PDF and (b) QQplot of the simulated ratio against observed ratio.

indicate that using a coarser mesh will result in reduced rainfall in the storm center and increased asymmetry with more rainfall in the front right quadrant and less rainfall in the left rear quadrant of the storm. As TCRM's overestimation of rainfall around and within the RMW is likely caused by the model's oversensitivity to the effect of the large radial gradient of the wind, a coarse grid will reduce the numerically computed wind gradient and thus reduce the estimated rainfall in the TC

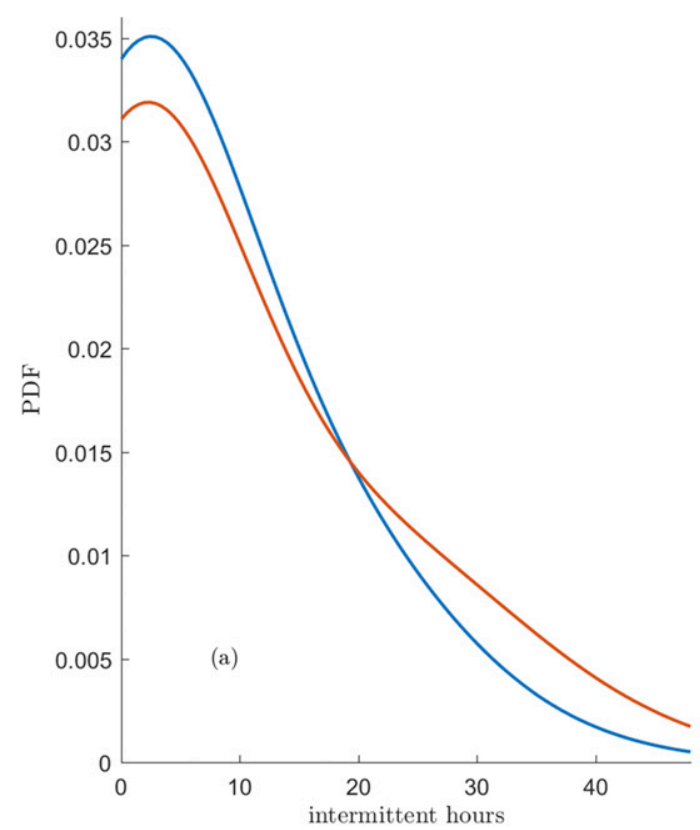

center. When the total rainfall is reduced around the TC center, the asymmetry induced by the effect of TC motion is enhanced proportionally.

As shown in Fig. 17, the annual TC rainfall in the two coarse simulations are similar to Fig. 6, but using a coarse mesh results in underestimation of rainfall for mountainous areas, although the results for coastal locations compare well with both the fine grid simulation and SRO. This underestimation of rainfall in mountainous areas is

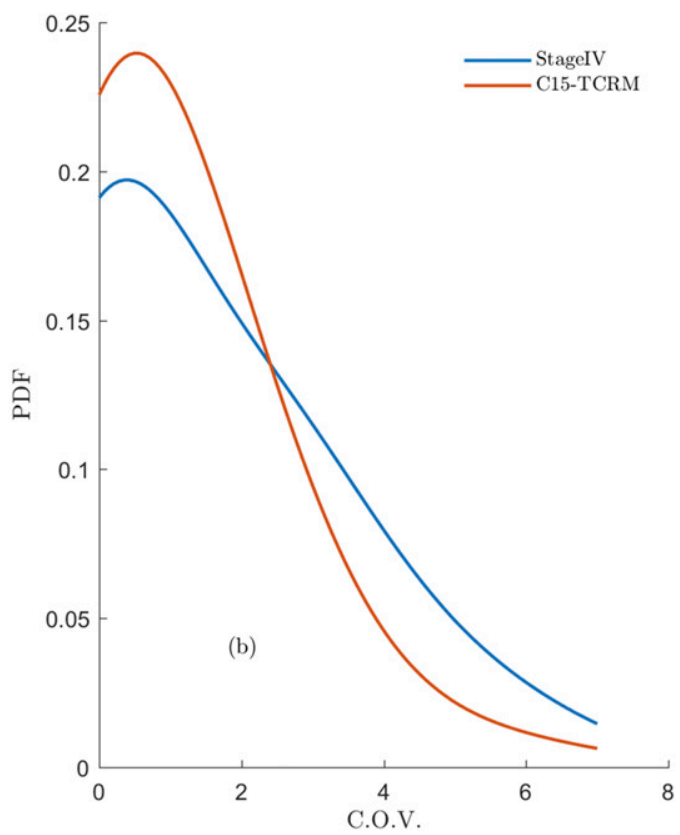

FIG. 14. PDF of (a) simulated and observed intermittent hours and (b) coefficient of variation of TC rainfall time series. 

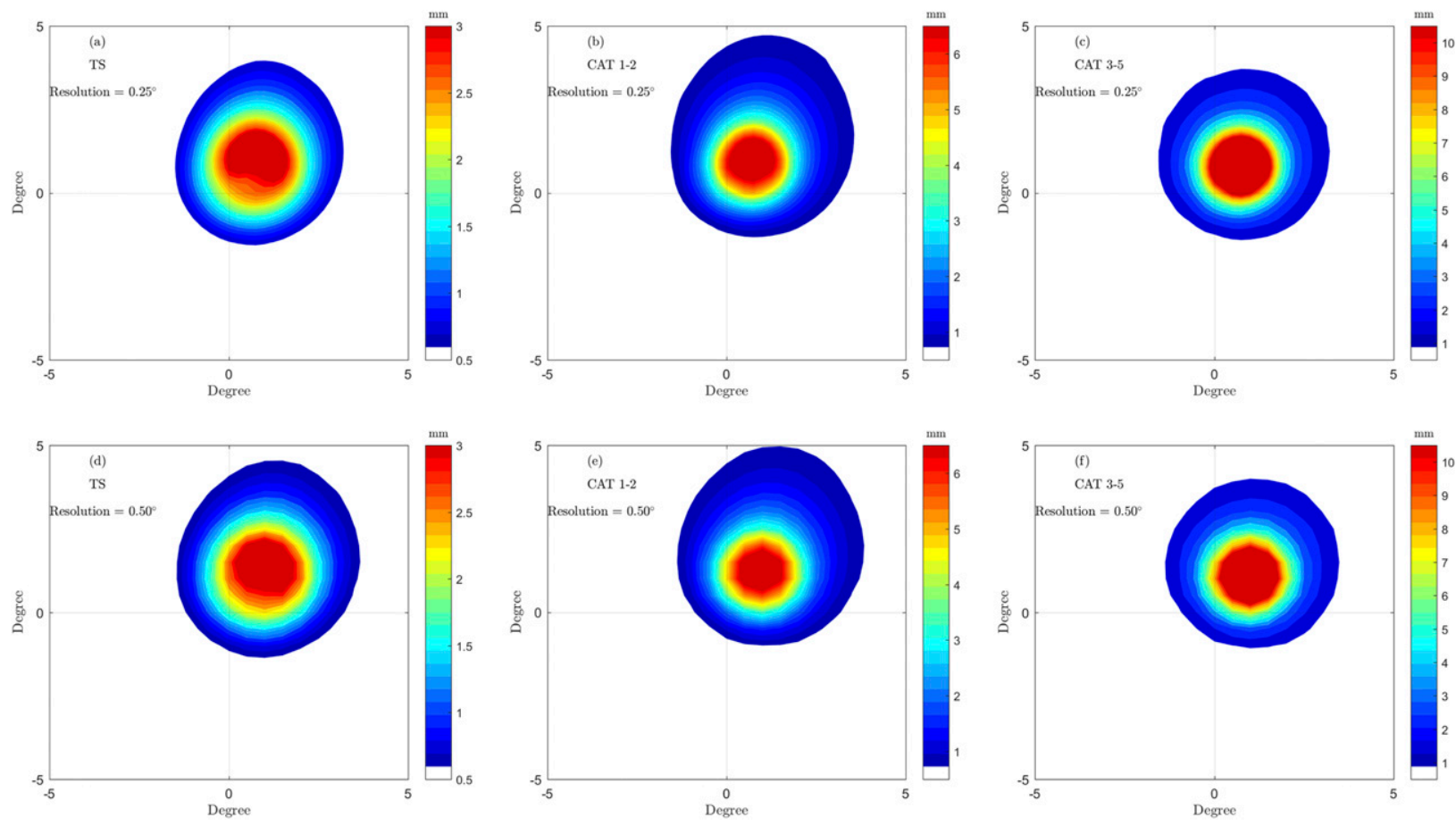

FIG. 15. As in Fig. 4, but for different simulation resolutions. Storm averaged rainfall simulated by TCRM with a $0.25^{\circ} \times 0.25^{\circ}$ horizontal resolution for (a) TS, (b) CAT1-2, and (c) CAT3-5. Storm averaged rainfall simulated by TCRM with a $0.5^{\circ} \times 0.5^{\circ}$ resolution for (d) TS, (e) CAT1-2, and (f) CAT3-5.

induced because the coarse grid cannot capture the relatively large gradient of drag coefficient in mountainous areas. Future work to improve the numerical performance of TCRM may consider smoothing the input wind profile or using a nested mesh for simulation. Adopting a coarser mesh in the center of TCs will reduce the overestimated rainfall around the RMW, and a fine grid can be used in outer radii to better capture the topographic effect. U.S. landfalling TCs usually interact with topography at their periphery, as statistically more TCs stay close to the coast than move to the inland mountainous areas.

\section{b. Comparison with previous research}

Previous studies have evaluated TCRM in different ways. Lu et al. (2018) evaluated TCRM with WRF simulations based on two U.S. landfalling TCs. They found that TCRM performs generally well in reproducing the total rainfall distribution for the two TCs studied. In their study, they found that the $\mathrm{H} 80$ wind profile performs the best in driving TCRM; in our study, however, we found that the $\mathrm{C} 15$ wind profile renders better simulation results. The difference may occur for two reasons. First, the wind field of the two storms in Lu et al. (2018) at the time period selected may be more suitably represented by the H80 model. In Fig. 9 in Lu et al. (2018), they found that the $\mathrm{H} 80$ wind profile matches with the observation better for the two TCs they studied. However, as found in Chavas and Lin (2016), the C15 wind profile model compares relatively well with the observation for a large set of TCs. Second, Lu et al. (2018) used a constant drag coefficient in the simulations while in this study we applied a geographically variable drag coefficient. Given the sensitivity of TCRM to surface drag, the different drag coefficient representations could contribute significantly to the discrepancy of the results from the two studies. Feldmann et al. (2019) used synthetic storms coupled with TCRM to compare the simulated and observed TC rainfall climatology. They found that TCRM produced satisfactory simulations for locations along the coast but not for regions further inland, a finding that may be caused by both sampling uncertainties and intrinsic limitations of TCRM for regions with large drag coefficients. The same feature is also found by this study that TCRM usually performs well in coastal regions but less well in mountainous regions.

\section{Conclusions}

In this study, we analyzed rainfall from 393 TCs in the NA from 1999 to 2018 and compared the TCRM simulations with RCLIPER simulations and satellite and 

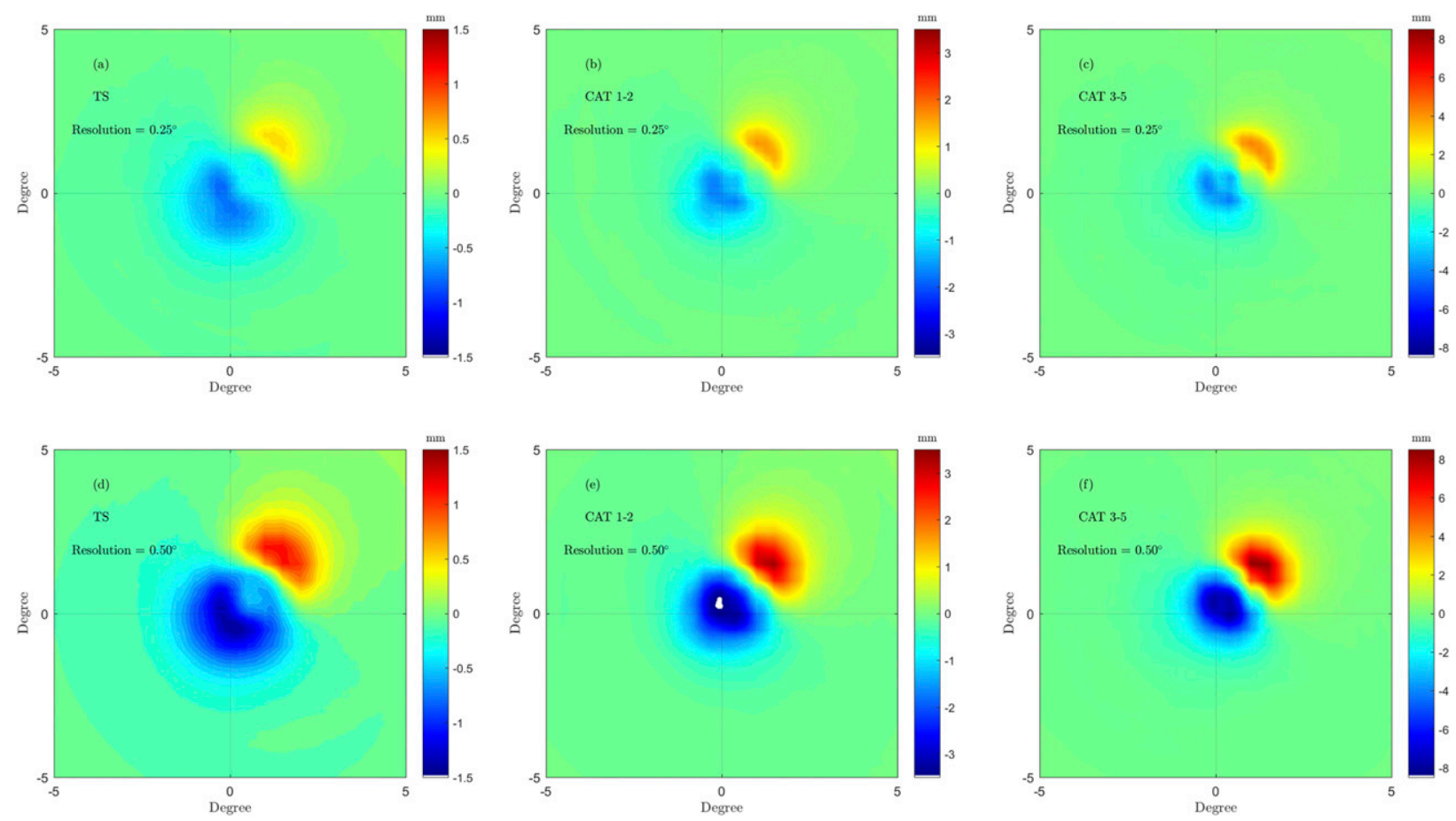

FIG. 16. Difference in TC-centered averaged rainfall between coarse grid simulation and fine grid simulations. Difference between the simulation with a $0.25^{\circ} \times 0.25^{\circ}$ horizontal resolution and the fine grid simulation for (a) TS, (b) CAT1-2, and (c) CAT3-5. Difference between the simulation with a $0.5^{\circ} \times 0.5^{\circ}$ horizontal resolution and the fine grid simulation for (d) TS, (e) CAT1-2, and (f) CAT3-5.

radar rainfall observations. Major findings of this study are summarized below:

1) Among the four wind profile models tested in this study, the $\mathrm{C} 15$ wind profile model preforms the best in driving TCRM, given its credible representation of the wind profile both around the RMW and in the region of outer radii. Accurately capturing the rainfall in outer radii is important in simulating STR and cumulated rainfall at specific locations. The coupled
C15-TCRM also performs better than the RCLIPER model in nearly all metrics.

2) C15-TCRM shows generally satisfactory ability to simulate rainfall from TCs that have a coherent and compact structure, with limitations in simulating rainfall from TCs interacting with other systems (e.g., Hurricane Harvey in Fig. 1) and extratropical transitioning TCs (e.g., Hurricane Irene in Fig. 1). The modeled STR compares well with SRO, although with more extremes, and has a light tail distribution,
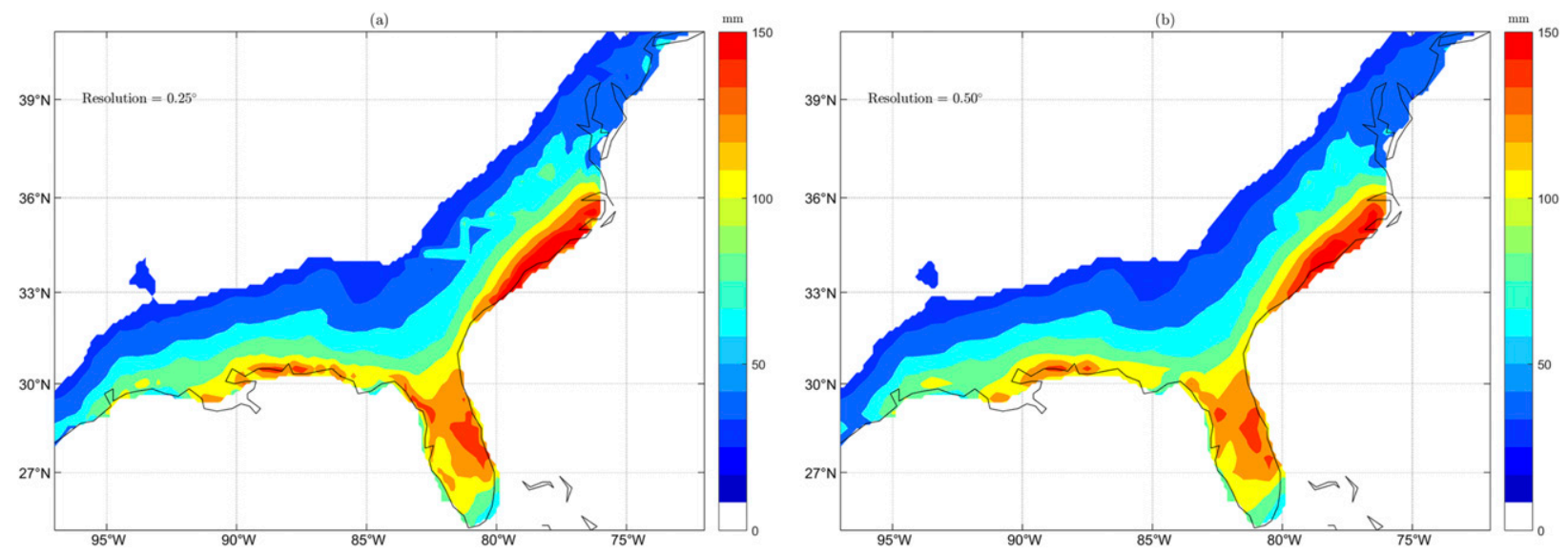

FIG. 17. As in Fig. 6, but with simulation resolution of (a) $0.25^{\circ} \times 0.25^{\circ}$ and (b) $0.5^{\circ} \times 0.5^{\circ}$. 
similar to SRO. For the rainfall structure, C15TCRM tends to overestimate the rainfall in the inner core region and slightly underestimate the rainfall in the outer region of TCs. C15-TCRM captures the $2 \mathrm{D}$ extent of TC rainfall and reproduces the observed forward-to-forward-right enhancement of rainfall. The simulated rainfall structure, however, is less asymmetric than SRO.

3) Geographically, C15-TCRM can capture relatively well the rainfall distribution along the U.S. East Coast, the Gulf Coast, and the Appalachians although the model underestimates the inland extent of TC rainfall and slightly overestimates rainfall in Florida, compared to SRO. A close comparison with the higher-resolution Stage IV indicates that the model may still underestimate spatial maximums especially in mountainous regions. In addition, TCRM has difficulties in accurately simulating TC rainfall in higher latitudes, possibly a consequence of not capturing the effects of extratropical transition.

4) Temporally, C15-TCRM can capture well the interannual variability of TC rainfall, measured by the annual total rainfall and the total rainfall scaled by the annual TC number or PDI. The model can capture relatively well the average pattern of the rainfall time series as the storm approaches a POI, although it produces a slightly delayed and overestimated rainfall peak at the POI compared to the Stage IV observation. The model has difficulties in capturing short-term (e.g., $1 \mathrm{~h}$ ) extreme rainfall, as the model lacks a representation of local and short-time-scale convections.

This study shows that a physics-based simplified TC rainfall model can produce major climatological features of TC rainfall, performing better than pure statistical models. Given the simplicity of TCRM, it has difficulties in simulating TC rainfall features related to extratropical transition or small-scale convective rainfall processes. It is neither computationally efficient nor physically feasible to include dynamic representations of such micro or mesoscale processes in TCRM, but it is of interest for future research to statistically capture these rainfall variations and to combine statistical and physical models to better simulate TC rainfall. Future research should also focus on coupling TCRM with different synthetic storm models and hydrologic models to study the risk of TC rainfall as well as flooding in current and future projected climates.

Acknowledgments. This material is based upon work supported by the National Science Foundation (NSF award 1520683) and by the U.S. Army Corps of Engineers (USACE) Flood and Coastal Systems R\&D Program through the Oak Ridge Institute for Science and Education (ORISE) Research Participation Program as part of an interagency agreement between the U.S. Department of Defense (DOD) and the U.S. Department of Energy (DOE). ORISE is managed by ORAU under DOE contract DE-SC0014664. All opinions expressed in this paper are the author's and do not necessarily reflect the policies and views of NSF, USACE, DOD, DOE, or ORAU/ORISE. We thank Kerry Emanuel (MIT) for providing us with the TCRM algorithm and advising us on its application.

Data Availability Statement. The datasets used in this study can be obtained from the sources provided in section 2 .

\section{REFERENCES}

Atallah, E. H., and L. F. Bosart, 2003: The extratropical transition and precipitation distribution of Hurricane Floyd (1999). Mon. Wea. Rev., 131, 1063-1081, https://doi.org/10.1175/ 1520-0493(2003)131<1063:TETAPD > 2.0.CO;2.

Bacmeister, J. T., K. A. Reed, C. Hannay, P. Lawrence, S. Bates, J. E. Truesdale, N. Rosenbloom, and M. Levy, 2018: Projected changes in tropical cyclone activity under future warming scenarios using a high-resolution climate model. Climatic Change, 146, 547-560, https://doi.org/ 10.1007/s10584-016-1750-x.

Berg, W., T. L'Ecuyer, and C. Kummerow, 2006: Rainfall climate regimes: The relationship of regional TRMM rainfall biases to the environment. J. Appl. Meteor. Climatol., 45, 434-454, https://doi.org/10.1175/JAM2331.1.

Blake, E. S., and D. A. Zelinsky, 2018: National Hurricane Center tropical cyclone report: Hurricane Harvey. NOAA/NWS Rep. AL092017, 45 pp., https://www.nhc.noaa.gov/data/tcr/ AL092017_Harvey.pdf.

Braun, S. A., and L. Wu, 2007: A numerical study of Hurricane Erin (2001). Part II: Shear and the organization of eyewall vertical motion. Mon. Wea. Rev., 135, 1179-1194, https:// doi.org/10.1175/MWR3336.1.

Chavas, D. R., and N. Lin, 2016: A model for the complete radial structure of the tropical cyclone wind field. Part II: Wind field variability. J. Atmos. Sci., 73, 3093-3113, https://doi.org/ 10.1175/JAS-D-15-0185.1.

,-- , and K. Emanuel, 2015: A model for the complete radial structure of the tropical cyclone wind field. Part I: Comparison with observed structure. J. Atmos. Sci., 72, 3647-3662, https:// doi.org/10.1175/JAS-D-15-0014.1.

Chen, S. S., J. A. Knaff, and F. D. Marks Jr., 2006: Effects of vertical wind shear and storm motion on tropical cyclone rainfall asymmetries deduced from TRMM. Mon. Wea. Rev., 134, 3190-3208, https://doi.org/10.1175/MWR3245.1.

Cheung, K. K. W., L.-R. Huang, and C.-S. Lee, 2008: Characteristics of rainfall during tropical cyclone periods in Taiwan. Nat. Hazards Earth Syst. Sci., 8, 1463-1474, https://doi.org/10.5194/ nhess-8-1463-2008.

Dee, D. P., and Coauthors, 2011: The ERA-Interim reanalysis: Configuration and performance of the data assimilation 
system. Quart. J. Roy. Meteor. Soc., 137, 553-597, https:// doi.org/10.1002/qj.828.

Emanuel, K., 2004: Tropical cyclone energetics and structure. Atmospheric Turbulence and Mesoscale Meteorology, E. Fedorovich, R. Rotunno, and B. Stevens, Eds., Cambridge University Press, 165-191, https://doi.org/ 10.1017/CBO9780511735035.010.

, 2005: Increasing destructiveness of tropical cyclones over the past 30 years. Nature, 436, 686-688, https://doi.org/10.1038/ nature 03906

— 2006: Climate and tropical cyclone activity: A new model downscaling approach. J. Climate, 19, 4797-4802, https:// doi.org/10.1175/JCLI3908.1.

— 2017: Assessing the present and future probability of Hurricane Harvey's rainfall. Proc. Natl. Acad. Sci. USA, 114, 12 681-12 684, https://doi.org/10.1073/pnas.1716222114.

_- , and R. Rotunno, 2011: Self-stratification of tropical cyclone outflow. Part I: Implications for storm structure. J. Atmos. Sci., 68, 2236-2249, https://doi.org/10.1175/JASD-10-05024.1.

_ , R. Sundararajan, and J. Williams, 2008: Hurricanes and global warming: Results from downscaling IPCC AR4 simulations. Bull. Amer. Meteor. Soc., 89, 347-368, https://doi.org/ 10.1175/BAMS-89-3-347.

Esau, I. N., 2004: Parameterization of a surface drag coefficient in conventionally neutral planetary boundary layer. Ann. Geophys., 22, 3353-3362, https://doi.org/10.5194/angeo-22-3353-2004.

Feldmann, M., K. Emanuel, L. Zhu, and U. Lohmann, 2019: Estimation of Atlantic tropical cyclone rainfall frequency in the United States. J. Appl. Meteor. Climatol., 58, 1853-1866, https://doi.org/10.1175/JAMC-D-19-0011.1.

Gori, A., N. Lin, and J. Smith, 2020: Assessing compound flooding from landfalling tropical cyclones on the North Carolina coast. Water Resour. Res., 54, e2019WR026788, https://doi.org/ 10.1029/2019WR026788.

Harr, P. A., and R. L. Elsberry, 2000: Extratropical transition of tropical cyclones over the western North Pacific. Part I: Evolution of structural characteristics during the transition process. Mon. Wea. Rev., 128, 2613-2633, https://doi.org/ 10.1175/1520-0493(2000)128<2613:ETOTCO >2.0.CO;2.

Holland, G. J., 1980: An analytical model of the wind and pressure profiles in hurricanes. Mon. Wea. Rev., 108, 1212-1218, https://doi.org/10.1175/1520-0493(1980)108<1212:AAMOTW > 2.0.CO;2.

Houze, R. A., 2010: Clouds in tropical cyclones. Mon. Wea. Rev., 138, 293-344, https://doi.org/10.1175/2009MWR2989.1.

Jing, R., and N. Lin, 2020: An environment-dependent probabilistic tropical cyclone model. J. Adv. Model. Earth Syst., 12 e2019MS001975, https://doi.org/10.1029/2019MS001975.

Kalnay, E., and Coauthors, 1996: The NCEP/NCAR 40-Year Reanalysis Project. Bull. Amer. Meteor. Soc., 77, 437-471, https://doi.org/10.1175/1520-0477(1996)077<0437:TNYRP> 2.0.CO;2.

Knaff, J. A., and R. M. Zehr, 2007: Reexamination of tropical cyclone wind-pressure relationships. Wea. Forecasting, 22, 71-88, https://doi.org/10.1175/WAF965.1.

Knapp, K. R., M. C. Kruk, D. H. Levinson, H. J. Diamond, and C. J. Neumann, 2010: The International Best Track Archive for Climate Stewardship (IBTrACS): Unifying tropical cyclone data. Bull. Amer. Meteor. Soc., 91, 363-376, https://doi.org/ 10.1175/2009BAMS2755.1.

Langousis, A., and D. Veneziano, 2009a: Theoretical model of rainfall in tropical cyclones for the assessment of long-term risk. J. Geophys. Res., 114, D02106, https://doi.org/10.1029/ 2008JD010080.

- , and — 2009b: Long-term rainfall risk from tropical cyclones in coastal areas. Water Resour. Res., 45, W11430, https:// doi.org/10.1029/2008WR007624.

Lee, C. Y., M. K. Tippett, A. H. Sobel, and S. J. Camargo, 2018: An environmentally forced tropical cyclone hazard model. J. Adv. Model. Earth Syst., 10, 223-241, https://doi.org/ 10.1002/2017MS001186.

Lin, Y., and K. E. Mitchell, 2005: The NCEP Stage II/IV hourly precipitation analyses: Development and applications. 19th Conf. on Hydrology, San Diego, CA, Amer. Meteor. Soc., 1.2, https://ams.confex.com/ams/Annual2005/techprogram/ paper_83847.htm.

Liu, M., and J. A. Smith, 2016: Extreme rainfall from landfalling tropical cyclones in the eastern United States: Hurricane Irene (2011). J. Hydrometeor., 17, 2883-2904, https://doi.org/ 10.1175/JHM-D-16-0072.1.

—, G. A. Vecchi, J. A. Smith, and H. Murakami, 2017: The present-day simulation and twenty-first-century projection of the climatology of extratropical transition in the North Atlantic. J. Climate, 30, 2739-2756, https://doi.org/10.1175/ JCLI-D-16-0352.1.

,,,--- and -2018 : Projection of landfalling-tropical cyclone rainfall in the eastern United States under anthropogenic warming. J. Climate, 31, 7269-7286, https://doi.org/ 10.1175/JCLI-D-17-0747.1.

_- L. L. Yang, J. A. Smith, and G. A. Vecchi, 2020: Response of extreme rainfall for landfalling tropical cyclones undergoing extratropical transition to projected climate change: Hurricane Irene (2011). Earth's Future, 8, e2019EF001360, https://doi.org/10.1029/2019EF001360.

Lonfat, M., F. D. Marks, and S. S. Chen, 2004: Precipitation distribution in tropical cyclones using the Tropical Rainfall Measuring Mission (TRMM) microwave imager: A global perspective. Mon. Wea. Rev., 132, 1645-1660, https://doi.org/ 10.1175/1520-0493(2004)132<1645:PDITCU>2.0.CO;2.

, R. Rogers, T. Marchok, and F. D. Marks, 2007: A parametric model for predicting hurricane rainfall. Mon. Wea. Rev., 135, 3086-3097, https://doi.org/10.1175/MWR3433.1.

Lu, P., N. Lin, K. Emanuel, D. Chavas, and J. Smith, 2018: Assessing hurricane rainfall mechanisms using a physics-based model: Hurricanes Isabel (2003) and Irene (2011). J. Atmos. Sci., 75, 2337-2358, https://doi.org/10.1175/JAS-D-17-0264.1.

Risser, M. D., and M. F. Wehner, 2017: Attributable human-induced changes in the likelihood and magnitude of the observed extreme precipitation during hurricane Harvey. Geophys. Res. Lett., 44, 12 457-12 464, https://doi.org/10.1002/2017GL075888.

Rodríguez-Iturbe, I., B. Febres De Power, and J. B. Valdes, 1987: Rectangular pulses point process models for rainfall: Analysis of empirical data. J. Geophys. Res., 92, 9645-9656, https:// doi.org/10.1029/JD092iD08p09645.

Rogers, R., S. Chen, J. Tenerelli, and H. Willoughby, 2003: A numerical study of the impact of vertical shear on the distribution of rainfall in Hurricane Bonnie (1998). Mon. Wea. Rev., 131, 1577-1599, https://doi.org/10.1175//2546.1.

Shapiro, L. J., 1983: The asymmetric boundary layer under a translating hurricane. J. Atmos. Sci., 40, 1984-1998, https://doi.org/ 10.1175/1520-0469(1983)040<1984:TABLFU>2.0.CO;2.

Touma, D., S. Stevenson, S. J. Camargo, D. E. Horton, and N. S. Diffenbaugh, 2019: Variations in the intensity and spatial extent of tropical cyclone precipitation. Geophys. Res. Lett., 46, 13 992-14 002, https://doi.org/10.1029/2019GL083452. 
Tuleya, R. E., M. DeMaria, and R. J. Kuligowski, 2007: Evaluation of GFDL and simple statistical model rainfall forecasts for US landfalling tropical storms. Wea. Forecasting, 22, 56-70, https:// doi.org/10.1175/WAF972.1.

Vecchi, G. A., T. L. Delworth, H. Murakami, S. D. Underwood, A. T. Wittenberg, F. Zeng, and X. Yang, 2019: Tropical cyclone sensitivities to $\mathrm{CO}_{2}$ doubling: Roles of atmospheric resolution, synoptic variability and background climate changes. Climate Dyn., 53, 5999-6033, https://doi.org/10.1007/s00382-019-04913-y.

Willoughby, H. E., F. D. Marks, and R. J. Feinberg, 1984: Stationary and moving convective bands in hurricanes. J. Atmos. Sci., 41, 3189-3211, https://doi.org/10.1175/15200469(1984)041<3189:SAMCBI > 2.0.CO;2.
Wright, D. B., T. R. Knutson, and J. A. Smith, 2015: Regional climate model projections of rainfall from U.S. landfalling tropical cyclones. Climate Dyn., 45, 3365-3379, https://doi.org/ 10.1007/s00382-015-2544-y.

Yang, M. J., S. A. Braun, and D. S. Chen, 2011: Water budget of Typhoon Nari (2001). Mon. Wea. Rev., 139, 3809-3828, https:// doi.org/10.1175/MWR-D-10-05090.1.

Zhang, Q., L. Wu, and Q. Liu, 2009: Tropical cyclone damages in China 1983-2006. Bull. Amer. Meteor. Soc., 90, 489-496, https://doi.org/10.1175/2008BAMS2631.1.

Zhu, L., S. M. Quiring, and K. A. Emanuel, 2013: Estimating tropical cyclone precipitation risk in Texas. Geophys. Res. Lett., 40, 6225-6230, https://doi.org/10.1002/2013GL058284. 